\title{
NATURALEZA JURÍDICA DEL SEGURO DE VIDA GRUPO DEUDORES *
}

\section{LEGAL NATURE OF THE GROUP CREDIT LIFE INSURANCE}

\author{
FELIPE TABARES CORTÉS ${ }^{* *}$
}

Fecha de recepción: 12 de septiembre de 2017

Fecha de aceptación: 4 de abril de 2018

Disponible en línea: 30 de junio de 2018

\section{Para Citar este articulo/To cite this article}

Tabares Cortes, Felipe, Naturaleza jurídica del seguro de vida grupo Deusores, 48 Rev.Ibero-Latinoam.Seguros, 63-104 (2018). https://doi. org/10.11144/Javeriana.ris48.njsv

doi:10.11144/Javeriana.ris48.njsv

* Reseña crítica y doctrinal sobre dos recientes providencias de la Corte Suprema de Justicia sobre el Seguro de Vida Grupo Deudores (Corte Suprema de Justicia, Sala Civil, 14 de marzo de 2017, Exp. SC3530-2017, MP. Álvaro Fernando García Restrepo y Auto de 17 de abril de 2017, Exp. SC35302017, M. Aroldo Wilson Quiroz Monsalvo).

** Abogado de la barra de Paris y de Colombia, especialista en Derecho Médico de la Universidad del Rosario, Maestría en Derecho de Seguros de la Université Lyon III Jean Moulin, Curso de Preparación del Centro Regional de Formación de Abogados de la Université Paris II PanthéonAssas, Summer Academy on International Investment Law and Disputes Settlement, Kuala Lumpur Regional Centre for Arbitration, Malasia. Contacto: felipetaba@gmail.com www. fr.linkedin.com/in/ felipetabarescortes 


\section{RESUMEN}

El seguro de vida grupo deudores protege la entidad bancaria asegurada contra el riesgo de pérdida que puede causar el deceso o incapacidad del deudor, asegurando entonces el reembolso de la deuda. En este esquema, el tomador es el banco que al mismo tiempo tiene la calidad de beneficiario. Esta particularidad del contrato de seguro vida grupo deudores dificulta el entendimiento que tradicionalmente se tiene de la noción de parte en el contrato de seguro colectivo. Más aun, la interpretación que al respecto ha hecho la jurisprudencia no ha servido para aclarar el derecho que tienen los deudores respecto del asegurador o el banco en este tipo de contratos. Después de describir la interpretación de la Corte Suprema de Justicia de Colombia sobre las principales reglas del contrato de seguro de vida grupo y de su comparación con las de las cortes de Francia y de Singapur, el autor describe la nueva teoría del banco-tomador como un intermediario en la distribución del seguro de vida grupo deudores, buscando con ello simplificar los problemas que actualmente presenta este contrato en nuestro país.

Palabras clave: Seguro colectivo; seguro de grupo; seguro de vida grupo deudores; noción de asegurado beneficiario; derechos del deudor; responsabilidad del banco; intermediarios; derecho comparado; Francia, Singapur. 


\begin{abstract}
Group credit life insurance protects the insured bank against the risk of loss arising from death or disability of the borrower, ensuring repayment of the debt. In this scheme, the policyholder is the credit institution and in the same time, the beneficiary. This specific situation challenges the traditional notion of contracting party in the insurance contract. Furthermore, the actual caselaw approaches to this contract did not elucidate the right of borrowers against the insurer or the bank under the group insurance contract. After depicting the Colombian Supreme Court's understanding about principal rules of the group credit life insurance, as well as those of the French and Singaporean Courts, the author describes the new theory of the bank as an insurance intermediary in the distribution of the group credit life insurance, aiming to simplify actual problems of this contract in Colombia.
\end{abstract}

Keywords: Group insurance; group credit life insurance; notion of insuredbeneficiary; group insurance; borrower's rights; bank liability; intermediaries; comparative law; France; Singapore.

\title{
SUMARIO
}

INTRODUCCIÓN. I. NACIMIENTO DEL CONTRATO. A. Principios generales. 1. Contenido contractual. a. Definición del amparo. b. Objeto del seguro. 2. Extensión del amparo. a. Interés asegurable. b. Riesgos asegurados. B. Formación del contrato. 1. Requisitos. a. Declaración de riesgos. b. Afiliación de deudores. 2. Aceptación del asegurador. a. Adhesión del deudor. b. Pago de la prima. II. FUNCIONAMIENTO DEL CONTRATO. A. Operación del contrato. 1. Ámbito de la garantía. a. Naturaleza de la prestación. b. Valor asegurado. 2. Realización del riesgo. a. Declaración del siniestro. b. Pago de la prestación. B. Efectos del contrato. 1. Facultades y límites de las partes. a. Responsabilidad civil del banco. b. Derechos del deudor. 2. Esquema contractual. a. Un contrato único o contratos sucesivos. b. El banco como intermediario de seguros 


\section{INTRODUCCIÓN}

La naturaleza de las relaciones que unen los diferentes participantes a la operación de seguro de vida grupo deudores ha sido objeto de amplios debates nacionales y extranjeros. A pesar de que esta operación económica es de vieja data, su calificación jurídica y su naturaleza son difícilmente identificables puesto que exceden los esquemas propios a la noción tradicional de este contrato y de la cual es tributaria nuestro Código de Comercio. No es una sorpresa entonces que el seguro de vida grupo deudores genere gran dificultad a los jueces colombianos para establecer su naturaleza jurídica y poder así resolver los litigios que se elevan por los asegurados contra las entidades crediticias y las aseguradoras $^{1}$. En el curso de los litigios objeto de estudio, que versan sobre el seguro de vida grupo deudores, se presentaron teorías divergentes sobre la naturaleza del contrato, las cuales son utilizadas para resolver las preguntas referentes a quienes son las personas legitimadas para reclamar la indemnización, así como respecto de las cargas y las responsabilidades de cada contratante. En América Latina, como lo mencionó el profesor Christian Larroumet ${ }^{2}$, las cortes son muy ceñidas a nuestros códigos civiles que presentan esquemas clásicos que en ocasiones se revelan estrechos para analizar la multiplicidad de operaciones del tráfico moderno. Es el caso del seguro de vida grupo deudores, frente al cual se han utilizado figuras tradicionales de nuestros códigos, como lo es la estipulación por otro o la relatividad aquiliana ${ }^{3}$, sin que ninguna logre explicar su naturaleza sin por la misma vía sacrificar la realidad comercial y operacional subyacente. El objetivo del presente trabajo, más que repertoriar el grupo de normas que rigen el contrato de seguro de vida grupo deudores ${ }^{4}$, es identificar cual ha sido la posición cambiante

1 Como lo menciona la propia Corte Suprema de Justicia de Colombia, Corte Suprema de Justicia, Sala Civil, 29 de mayo de 2015, Exp. SC-6709-2015, MP. Jesús Vall de Rutén Ruíz, Salvamento de voto. En esta situación se encuentran igualmente los funcionarios de varias jurisdicciones desde que se comenzó con la reglamentación de este tipo de contratos, Greater detail on credit risk and political risk, in Ridley N. (2011) Insurance Disputes, Ch. 22, Insurance against pecuniary loss, 3rd Ed. i-Law, p. 20-26.

2 Conferencia inaugural de la Asociación de Juristas Franco-Colombianos, Paris 9 de junio de 2017, Première soirée de l'Association des Juristes franco-colombiens, www.juristesfrancocolombiens.com

3 Narváez Bonnet, J.E. (2013) Legitimación de la viuda y de los herederos bajo el seguro de vida grupo deudores, Revista Ibero-Latinoamericana de Seguros, RIS, Bogotá (Colombia), 39(22): 69-111, juliodiciembre de 2013.

4 Por la extensión del tema, no serán tratadas las Sentencias de la Delegatura de Asuntos Jurisdiccionales de la Superintendencia Financiera que han desarrollado una dogmática propia a estos contratos y que requiere de un estudio posterior, especialmente en lo que respecta a su entendimiento de la 
de la jurisprudencia de la Corte Suprema de Justicia colombiana y de cortes extranjeras, específicamente de Francia y Singapur, incluyendo los obiter dicta, frente a las nociones propias a este tipo de garantía. Así, estudiaremos en un primer momento cuales son las particularidades que rigen el nacimiento del seguro de vida grupo deudores (I) para en un segundo momento indagar cuál es en concreto la naturaleza jurídica y el modo operativo de este contrato en Colombia (II), lo que finalmente nos permitirá plantear una evolución teórica de origen extranjero y que consideramos es una solución adecuada para mantener el rendimiento ideal de esta figura jurídica (II).

\section{NACIMIENTO DEL CONTRATO}

En el esquema clásico el contrato nace del acuerdo de voluntades entre el asegurador y la entidad crediticia que exige a sus clientes la suscripción de un seguro de vida de deudores para la expedición del crédito. Así, al momento de formación del contrato de grupo, que requiere la voluntad no solo del asegurador (B), le preceden unos principios generales que condicionan el establecimiento del amparo (A).

\section{A. Principios generales}

El legislador Colombiano ${ }^{5}$ aprobado en este sentido por la Corte Suprema de Justicia en la Sentencia de 27 julio de $2015^{6}$ estableció unos principios que guían el contrato de seguro de vida grupo deudores como son la igualdad de acceso, la igualdad de información, la libertad y la objetividad en la selección del asegurador, la posibilidad de elección del

reticencia del asegurado y a la prescripción en el contrato de seguro de vida grupo deudores. No serán tampoco objeto de análisis las Sentencias de la Corte Constitucional porque el sustento fáctico es diferente, tratándose de situaciones de debilidad manifiesta del ciudadano, en las cuales las normas ordinarias del derecho de seguros deben ceder frente a postulados constitucionales de protección del individuo; se trata pues de un derecho especial de aplicación limitada (cf. Zarante Bahamón, G. (2016) Constitucionalización y protección de derechos fundamentales en el contrato de seguro: Análisis jurisprudencial-Corte Constitucional de Colombia, 45 Rev.Ibero-Latinoam.Seguros RIS, 233-268 y Manrique Chaves, D. M. (2016) La sobreconstitucionalización del derecho de seguros: El compañero permanente o cónyuge del mismo sexo como beneficiario a título legal en el seguro de vida, 44 Rev. Ibero-Latinoam.Seguros RIS, 91-139).

5 Decreto 384 de 1993, Decreto 673 de 2014, Numerales 6.3.3. y siguientes de la Circular Básica Jurídica de la Superintendencia Financiera y el artículo 100 del Estatuto Orgánico del Sistema Financiero, así como la Ley 1328 de 2009 tratándose del consumidor financiero. 
asegurador por parte del deudor, la unidad de la póliza y la periodicidad. Si con tales disposiciones normativas el Estado Colombiano optó por una protección reforzada del asegurado, ello no ha garantizado una utilización efectiva del contrato, lo que se evidencia en el alto número de procesos que se incoan al respecto, situación que ha suscitado entonces un intervencionismo acentuado de los jueces. Así, en diferentes pronunciamientos la jurisprudencia de la Corte Suprema de Justicia y la doctrina se han preocupado por establecer la noción del contenido contractual del seguro de vida grupo deudores (1) lo que ha necesitado de manera paralela determinar cuál es la extensión de la cobertura en este tipo de contratos (2).

\section{Contenido contractual}

La noción del contrato de seguro de vida grupo deudores está determinada por el grupo de reglas que rigen el funcionamiento del contrato y que constituyen los contornos ${ }^{7}$ dentro de los cuales la producción comercial del servicio debería tener lugar. Es por ello que se ha establecido una dogmática propia a este tipo de contratos, en primera medida respecto de la definición del amparo (a), así como respecto de objeto perseguido por este seguro (b).

\section{a. Definición del amparo}

El seguro de vida grupo deudores es una modalidad de seguro colectivo ${ }^{8}$ en la cual, ante el advenimiento de sucesos futuros que pongan en el riesgo el pago de un crédito, como el desempleo, la incapacidad o deceso ${ }^{9}$ afectando a un grupo de personas que son todas deudoras de un mismo acreedor, el asegurador cubre una suma equivalente al saldo insoluto del respectivo crédito. Para la Corte Suprema de Justicia en Sentencia 30 de junio de $2011^{10}$ este contrato cumple una función de garantía puesto que

7 La noción de objeto y causa comienzan, en los países de tradición napoleónica, a dejar el paso a una utilización más pragmática que teórica del concepto de contenido contractual: Rapport au Président de la République relatif à l'ordonnance $\mathrm{n}^{\circ}$ 2016-131 du 10 février 2016 portant réforme du droit des contrats, du régime général et de la preuve des obligations JORF $n^{\circ} 0035$ du 11 février 2016 texte $n^{\circ} 25$.

8 Narváez Bonnet, J. E. (2013). Legitimación de la viuda y de los herederos bajo el seguro de vida grupo deudores. Revista Ibero-Latinoamericana De Seguros, 22(39), 69-111.

9 Contrats emprunteurs (2017) Chapitre 1 Section 1, Dictionnaire permanent assurances, ElNet Editions Législatives.

10 Corte Suprema de Justicia, 30 de junio de 2011, Exp. 019-01, MP. Edgardo Villamil Portilla. 
ocurrido alguno de los riesgos el acreedor obtendrá la satisfacción de la deuda $^{11}$, dado que el asegurador asume el pago de ésta.

Sin embargo, para determinar sus elementos mínimos la Corte Suprema de Justicia ha necesitado identificar los elementos que lo diferencian de instituciones jurídicas vecinas. Así, en Sentencia de 23 de marzo de $2004^{12}$ la Sala Civil afirmó que la aseguradora, dentro del contrato de seguro de vida grupo deudores, no tiene la calidad de garante del pago de la obligación pues no es un tercero que se haya obligado solidaria o subsidiariamente junto con el deudor para la satisfacción de la obligación. De esta manera la aseguradora se compromete en virtud de un contrato y bajo unas condiciones específicas, pero no como si estuviera en igual grado siendo beneficiaria del crédito.

Recuerda la Corte Suprema de Justicia en Sentencia de 29 de agosto de $2000^{13}$ que el contrato de seguro de vida grupo deudores tiene unas características diferentes a un seguro de crédito. En efecto, el riesgo asumido por la compañía aseguradora en el contrato de seguro de vida grupo deudores no es la imposibilidad de pago del deudor, sino más bien el suceso incierto de la muerte del mismo y ello independientemente de si el patrimonio que éste deja permite que la acreencia le sea pagada a la entidad bancaria. No se trata pues, según la Corte, de cubrir la imposibilidad de pago del deudor, ya que en un tal caso se trataría de un seguro de carácter patrimonial como lo es el seguro de crédito. De otro lado, en la Sentencia de 27 julio de $2015^{14}$ la Sala Civil de la Corte concluyó que el contrato de seguro de vida grupo deudores es un contrato por cuenta ajena en el cual el banco, al tomar el seguro, traslada un riesgo que en principio no le es propio sino del deudor, es decir, la incapacidad de pago causada por el deceso o la invalidez.

\section{b. Objeto del seguro}

El crédito es un instrumento vital para la financiación de individuos y empresas. Pero este instrumento necesita de un respaldo para permitir

11 Concepto 2014105076-001 de 23 de diciembre de 2014 "Seguro de vida grupo deudores, amparos" Superintendencia Financiera de Colombia.

12 Corte Suprema de Justicia, 23 de marzo de 2004, Exp. 14576, MP. Silvio Fernando Trejos Bueno.

13 Corte Suprema de Justicia, 29 de agosto de 2000, Exp. 6379, MP. Jorge Santos Ballesteros.

14 Corte Suprema de Justicia, Sala Civil, 27 de julio de 2015 Exp. 179901 MP. Fernando Giraldo Gutiérrez. 
que el prestamista recupere su dinero en caso de falla del deudor. Si bien, existen otras formas en las cuales las entidades crediticias pueden permitir el recobro del empréstito, el crecimiento económico y el desarrollo de los sectores industriales hizo necesaria otra forma de cubrir los montos prestados en caso de insolvencia del deudor. Un ejemplo de esta restricción es la hipoteca que tiene una capacidad limitada de satisfacción de la deuda puesto que su efectividad exige costos y tiempo adicionales, mucha veces engorrosos ${ }^{15}$. Sin embargo, el seguro aparece como una forma de paliar las dificultades propias a la incapacidad de pago del deudor, sin que en su constitución o su puesta en marcha otros costos adicionales sean necesarios. La gestión colectiva de seguros permite moderar el costo operacional de la existencia del amparo, al mismo tiempo en que se realiza una cobertura extensa de riesgos. Así, la simplificación en la distribución de este producto disminuye el valor de las primas al mismo tiempo que mantiene un estándar de garantía y distribución. El objetivo del legislador, así como de los actores del mercado, es extender la inserción financiera en la sociedad al extender la cobertura a más personas o empresas y mejorar así su perfil crediticio. Sin duda alguna, es un instrumento importante que ha demostrado grandes ventajas, por ejemplo en el sector del crédito a la exportación, por solo citar uno ${ }^{16}$. Sin embargo, es necesario aclarar que, a pesar de que la tendencia es al aumento del uso del seguro en la sociedad a través de los nuevos canales y tecnologías ${ }^{17}$, respecto del seguro colectivo se registra una propensión internacional de exigencias jurídicas más estrictas ${ }^{18}$, situación a la cual no es ajena Colombia, como se verá en la Sección §II.B.2.a.

\section{Extensión del amparo}

Si la definición y el objeto del seguro de vida grupo deudores no generan mayor dificultad de análisis, la determinación de las personas que

15 Rojas López, Miguel David, Bran Rueda, Nelson Yovany, \& Rincón López, Carolina. (2013). Mortgage Financing Model For Housing. Case study: Mexico, Chile and Colombia. Revista Ingenierías Universidad de Medellín, 12(22), 97-108.

16 Donlon, R. L. (2016) Using trade credit insurance in the energy industry, Property Casualty 360 , LexisNexis UK, February 26, 2016.

17 Mejía Aramburo, S. (2017) La desintermediación en el contrato de seguro. De la bancaseguros al uso de red, Rev.Ibero-Latinoam. Seguros RIS, n. 46, 109-148.

18 Bury, B. (2014) L'inadéquation fonde l'obligation d'éclairer sur l'adéquation. Gazette du Palais, Lextenso, 22/07/2014, n 203, p. 32, GPL187m3. 
pueden acudir a solicitar el amparo ha generado gran discusión, por lo cual nosotros nos concentraremos únicamente en describir los rasgos generales del debate sobre el interés asegurable en nuestro país (a) para luego referirnos al tema de los riesgos asegurados (b).

\section{a. Interés asegurable}

La noción de interés asegurable en este tipo de contratos ha generado arduas discusiones jurisprudenciales y doctrinales, puesto que es la forma en la que en los procesos judiciales se expresa la pregunta de quién está autorizado a recibir la indemnización.

El interés asegurable en el contrato de seguro de vida grupo deudores es en primera medida la vida del deudor, aunque su estado de salud y su capacidad para el trabajo constituyen las demás garantías del contrato. Así lo recordó la Corte Suprema de Justicia en la Sentencia 16 de mayo de $2011^{19}$ según la cual el interés asegurable es la vida del deudor, y por esta razón éste tiene la calidad de asegurado dentro de la póliza. Pero no dudó la Corte en reconocer una concurrencia de intereses, en la Sentencia de 30 de junio de $2011^{20}$, puesto que además del deudor, el acreedor tiene un interés indirecto en la existencia del seguro. En efecto, hay un interés directo del deudor para no resultar afectado en caso de incapacidad, pero existe además un interés indirecto del banco acreedor, quien pretende sustraerse de los efectos del deceso o de la incapacidad de su cliente. Así, aunque no son excluyentes, estos intereses no tienen una correspondencia exacta, pues se sobrepone el interés del solvens al interés eventual del acreedor y es por ello que se exige contar con la aquiescencia del deudor, aquiescencia que se ve plasmada en la solicitud individual de ingreso que debe suscribir el candidato al crédito.

Esta perspectiva de intereses concurrentes pero dispares fue morigerada principalmente en la Sentencia de 27 de julio de $2015^{21}$ en la cual la Corte aprobó el análisis según el cual, en este tipo de seguros, tanto el acreedor como los deudores estaban a priori en condición de solicitar la

19 Corte Suprema de Justicia, 16 de mayo de 2011, Exp. 9221-01, MP. Ruth Marina Diaz Rueda.

20 Corte Suprema de Justicia, Sala Civil,30 de junio de 2011 Exp. 0019-01, MP. Edgardo Villamil Portilla.

21 Corte Suprema de Justicia, Sala Civil, 27 de julio de 2015 Exp. SC-9618-2015, MP. Fernando Giraldo Gutiérrez. 
reclamación a la aseguradora, ya que ambos tienen un interés asegurable. Sin embargo, aunque es evidente que los deudores contaban con una perspectiva de provecho por el pago del crédito, para los jueces, ello no los legitimó para acudir directamente ante la aseguradora y reclamar la indemnización, puesto que la ley prefiere a quien obra como tomador. Este análisis había sido validado por la doctrina, al considerar que la ley prefiere al acreedor, ya que éste tiene un interés asegurable en la vida de aquellas personas, cuya muerte o incapacidad puedan ocasionarle un perjuicio económico, esto es, los deudores ${ }^{22}$.

Sin embargo, algunas voces se oponen a una lectura estricta del texto de la ley. Para dos Magistrados ${ }^{23}$ de la Corte Suprema de Justicia, dicho interés no puede residir en el deudor, el cual no obtiene ninguna ventaja en cubrir una deuda luego de su muerte, de manera que si adquiere el seguro es porque éste es una imposición del banco para la obtención del crédito. Así, si el interés asegurable radica esencialmente en el banco y la prestación económica se limita al saldo debido, carece de sentido defender la tesis de que el seguro de vida grupo deudores es exclusivamente de personas y que no posee un carácter indemnizatorio. Frente al análisis adverso otro autor ${ }^{24}$ afirma (partiendo de lo decidido en de las Sentencias de 28 de julio de $2005^{25}$ y 15 de diciembre de $2008^{26}$ ) que desde un punto de vista puramente procedimental, el admitir un interés indiscutible de los causahabientes del deudor no tiene justificación suficiente, pues permitir su intervención únicamente adhesiva no les da la calidad de partes procesales para estar legitimados a reclamar la cobertura.

En algunas ocasiones, en la solicitud de cobertura, diligenciada por el deudor o por el banco, no se precisó la persona asegurada. En otros

22 Narváez Bonnet, J. E. (2013). Legitimación de la viuda y de los herederos bajo el seguro de vida grupo deudores. Revista Ibero-Latinoamericana De Seguros, 22(39), 69-111.

23 Salvamento de Voto de Ariel Salazar Ramírez y Luis Armando Tolosa Villabona en la Sentencia de la Corte Suprema de Justicia, Sala Civil, 29 de mayo de 2015, Exp. SC-6709-2015, MP. Jesús Vall de Rutén Ruíz.

24 Ramirez-Gómez, J.F. (2015) Legitimación del cónyuge sobreviviente y de los herederos con ocasión de los contratos de seguros de vida grupo deudores, Revista Ibero-Latinoamericana de Seguros RIS, 103-121 (2015).

25 Corte Suprema de Justicia. Sala de Casación Civil. 28 de julio de 2005, Expediente 449, M.P. Manuel Isidro Ardila Velásquez.

26 Corte Suprema de Justicia. Sala de Casación Civil. 15 de diciembre de 2008, Expediente 1021, M.P. Jaime Alberto Arrubla Paucar. 
casos se puso, o únicamente al banco, o únicamente al deudor. En otras ocasiones no se aportó al plenario ni la solicitud de cobertura ni el certificado individual ${ }^{27}$. Todas estas circunstancias explican que la pregunta de la persona que puede y tiene derecho de solicitar la garantía tenga gran relevancia, más aún si se tiene en cuenta que se trata de un contrato establecido entre tres personas, y no solo dos como es en la concepción del contrato en la tradición napoleónica clásica. Pero como se verá (Sección §II.B.2.b.) la discusión del derecho se desplaza a la de la carga o el deber de la persona que interviene en la formación del contrato.

\section{b. Riesgos asegurados}

Los riesgos asegurados están esencialmente vinculados a la vida del deudor, específicamente su deceso, invalidez, enfermedad profesional o incluso en el caso de desempleo, situaciones que le imposibilitan recibir la remuneración de su trabajo y le impiden consecuentemente el pago del crédito. Empero, cuando el contrato de seguro de vida no incluye una definición precisa del siniestro de invalidez objeto de la garantía, la Corte Constitucional, desde la Sentencia T-07 de $2015^{28}$ ha exigido que como mínimo se respeta el estándar del régimen de seguridad social en pensiones, es decir, que se exija que el asegurado sea calificado por lo menos con el $50 \%$ de pérdida de la capacidad laboral para que se pueda estructurar el riesgo asegurado.

Pero si el contrato de seguro incluye como definición de invalidez la imposibilidad absoluta de retomar una actividad profesional, ello excluye la posibilidad de la persona que fue reubicada continuando con una actividad laboral sedentaria de medio tiempo, como se definió por la Corte de Casación de Francia ${ }^{29}$. En igual sentido, en Singapur, la High Court en la Decisión NTUC Cooperative Insurance Commonwealth Enterprise Ltd $v$ Chiang Soong Chee [2007] ${ }^{30}$ exigió que el asegurado demuestre que está en incapacidad de desarrollar cualquier actividad profesional, para poder acceder a la garantía de invalidez.

27 Resumen de los casos de las sentencias de la Corte Suprema de Justicia de Colombia estudiados por el autor.

28 Corte Constitucional, Sentencia T-007 (40312013), ene. 15/15, M. P. Jorge Iván Palacio.

29 Cass. 1re civ., 22 janv. 2009, no 07-19.867.

30 NTUC Cooperative Insurance Commonwealth Enterprise Ltd v Chiang Soong Chee [2007] SGHC 222 


\section{B. Formación del contrato}

Las cláusulas del contrato, los requisitos de adhesión y la forma de distribución son establecidos entre la entidad crediticia y la aseguradora. Ello significa que el asegurado estuvo por fuera de la negociación del acuerdo $^{31}$, lo que ha motivado a los jueces a ejercer un intervencionismo centrado en proteger el consumidor de seguros y a identificar cuales las reglas propias al establecimiento del seguro, concretadas en los requisitos previos del contrato (1) como en aquellas circunstancias que permiten la aceptación del asegurador (2).

\section{Requisitos}

La suscripción de un contrato de seguros se caracteriza por la existencia de unas etapas precontractuales ineludibles para la compañía de seguros para poder verificar la asegurabilidad del cliente, a través de la declaración de riesgos (a) lo que determina posteriormente la afiliación de los deudores (b).

\section{a. Declaración de riesgos}

En un primer momento (Sentencia de 19 de mayo de $1999^{32}$ ) conceptuó la Corte Suprema de Justicia que la declaración de riesgos incumbe fundamentalmente al tomador. Pero en dicho caso, puesto que el formulario de la declaración de riesgos fue diligenciado directamente por la entidad crediticia, se juzgó que era a ésta a quien debían imponérsele las consecuencias de una reticencia en la información otorgada. Sin embargo, en el caso contrario, en el cual la declaración fue realizada por el deudor (Sentencia de la Corte Suprema de Justicia de 23 de marzo de 2004 $4^{33}$ ) no puede decirse que la entidad crediticia pierde la posibilidad de recuperar el valor prestado, porque si el asegurador objetó la garantía como consecuencia de la reticencia en la declaración de riesgos del asegurado, indico

31 Aunque le está permitido al candidato al crédito una cobertura externa a la ofrecida por el banco, caso en el cual el asegurado tiene un mayor margen de maniobra para adecuar las riesgos cubiertos y las condiciones de garantia a las exigencias de la entidad crediticia o sus preferencias personales.

32 Corte Suprema de Justicia, Sala Civil, 19 de mayo de 1999, Exp. 4923, MP. José Fernando Ramírez Gómez.

33 Corte Suprema de Justicia, Sala Civil, 23 de marzo de 2004, Exp. 14576, MP. Silvio Fernando Trejos Bueno. 
la Corte que el banco podrá perseguir la satisfacción de la obligación con el patrimonio de los otros deudores solidarios.

Adicionalmente, frente a la declaración de la modificación de riesgos en curso del contrato, si bien en la Sentencia de 19 de mayo de $1999^{34}$ afirmó la Corte que la conservación del estado del riesgo corresponde al asegurado o al tomador, según quien tenga la posibilidad de cumplir con un tal deber, posteriormente manifestó en la Sentencia de 6 de julio de $2007^{35}$ que, en aplicación del artículo 1060 del Código de Comercio, la obligación de mantener el riesgo asegurado no existe en los seguros de vida.

\section{b. Afiliación de deudores}

El grupo asegurable en el contrato de seguro de vida grupo deudores está conformado por personas naturales que son vinculadas bajo una misma personería jurídica o que tienen relaciones estables de la misma naturaleza con el tomador ${ }^{36}$. Pero antes de la integración del grupo se realiza una selección de candidatos a partir de las características necesarias a la expedición del amparo.

Esta selección se realiza entonces en primera medida en la revisión de un perfil crediticio por parte de la entidad bancaria. Posteriormente, la solicitud individual permite entre otras, determinar el monto máximo a asegurar, puesto que si existen dudas sobre dichos límites contractuales, como fue juzgado por la Corte Suprema de Justicia en la Sentencia de 16 de mayo de $2011^{37}$, será a través de este documento que se puede determinar cuál es el saldo de la deuda a cubrir por el asegurador. Pero no debe olvidarse que quien realiza en primera medida el trámite y que se presenta directamente frente al cliente es el banco y no la aseguradora ${ }^{38}$. Esta situación expone otro de los motivos de la complejidad propia a los seguros

34 Corte Suprema de Justicia, Sala Civil, 19 de mayo de 1999, Exp. 4923, MP. José Fernando Ramírez Gómez.

35 Corte Suprema de Justicia, Sala Civil, 6 de julio de 2007, Exp. 0359-01, MP. Carlos Ignacio Jaramillo Jaramillo.

36 Numeral 3.6.3.2. de la Capítulo 2o Título VI de la Circular Básica Jurídica de la Superintendencia Financiera.

37 Corte Suprema de Justicia, Sala Civil, 16 de mayo de 2011, Exp. 9221-01, MP. Ruth Marina Díaz Rueda.

38 En los casos en los cuales no se trata de una entidad bancassurance con ambas calidades. 
colectivos, puesto que a diferencia de cualquier otro contrato de seguro, en el seguro de vida grupo deudores es usualmente la entidad bancaria quien debe realizar las diligencias necesarias a la inclusión del deudor y quien dice suscripción del contrato, dice cumplimiento de las obligaciones de información del asegurado como se verá en la Sección §II.B.1.b.

\section{Aceptación del asegurador}

$\mathrm{Al}$ asegurador no se le impone la aceptación de un asegurado pues no se trata de un seguro obligatorio, en el cual el candidato al crédito hace parte de un grupo restringido, como lo es el empleado que debe ser asegurado por su empleador en el momento de suscribir un contrato de seguro en beneficio de sus trabajadores ${ }^{39}$. Sin embargo, en la mayoría de los casos la entidad bancaria exige, para el otorgamiento del préstamo, la suscripción de un contrato de seguro y es así que la póliza deviene en una condición de la existencia del crédito ${ }^{40}$. La aceptación del asegurador se consolida con la expedición del certificado individual de seguro ${ }^{41}$. Este certificado puede mencionar, como lo recordó la Corte en la Sentencia de 6 de julio de $2007^{42}$, dos personas aseguradas, específicamente el deudor y su cónyuge, situación que está expresamente codificada en la ley ${ }^{43}$. Además, se estableció en la Sentencia de 5 de mayo de $2014^{44}$, que si la entidad bancaria desconoció una cláusula del contrato de mutuo que restringía el desembolso de los dineros hasta tanto la compañía de seguros incluyera al usuario como asegurado, el banco debe hacerse cargo del siniestro que no fue cubierto por la compañía de seguros en razón a que el deudor no podía ser aceptado en el grupo. En cualquier caso, previo a la existencia del contrato debe cumplirse con las condiciones propias a la adhesión del deudor (a) lo cual exige perentoriamente el pago de la prima (b).

39 Kullman, J. et al. (2017) LamyLine, Lamy Assurances 2017, Wolters Kluwer France, n4606.

40 Ibidem.

41 El cual es obligatoriamente expedido por el asegurador, además de las condiciones generales y con la estipulación de la tarifa aplicable, como se establece en el artículo 120 del Estatuto Orgánico del Sistema Financiero.

42 Corte Suprema de Justicia, Sala Civil, 6 de julio de 2007, Exp. 0359-01, MP. Carlos Ignacio Jaramillo Jaramillo.

43 Artículo 3.6.3.5.6. de la Capítulo $2^{\circ}$ Título VI de la Circular Básica Jurídica de la Superintendencia Financiera.

44 Corte Suprema de Justicia, Sala Civil, 5 de mayo de 2014 Exp. SC-5189-2014, MP. Margarita Cabello Blanco. 


\section{a. Adhesión del deudor}

Si la lista de clientes asegurables es establecida por el banco, la aceptación definitiva no puede tener lugar sino una vez el asegurador determine que el candidato cumple con las condiciones para ingresar a la mutualidad. Esta es una de las razones por las cuales a la compañía de seguros le es permitido solicitar todas las pruebas que sean necesarias para determinar la asegurabilidad del riesgo ${ }^{45}$. Así, el legislador previene busca prevenir la selección adversa del asegurador ${ }^{46}$. Uno de los aspectos que ha generado discusión son las condiciones referentes a la edad y al estado de salud del asegurado. En efecto, la inexactitud en la edad puede generar la nulidad del contrato, como ocurrió en la Sentencia de 29 de mayo de $2015^{47}$ o la reticencia en la información sobre el estado de salud del deudor en la Sentencia de 4 de marzo de $2016^{48}$, pero la ley exige que en el Certificado Individual se expresen las clausulas sobre las consecuencias que trae la reticencia del asegurado ${ }^{49}$. De otro lado, si el Certificado Individual comporta errores, como la falta de individualización de los propietarios del inmueble o que figurara al mismo tiempo como asegurado y beneficiario el banco, como ocurrió en el caso de la Sentencia de 27 de julio de $2015^{50}$, ello de ninguna manera significa que los deudores carecieran de la calidad de asegurados del contrato.

\section{b. Pago de la prima}

En un contrato individual es el tomador quien está en la obligación de pagar la prima ${ }^{51}$. Sin embargo, la ley, teniendo en cuanta las particularidades propias al contrato de seguro grupo, autorizó su pago, sea por el tomador o por el asegurado, calificándolas así de contributivas o no

45 Numeral 3.6.3.3 de la Capítulo 2o Título VI de la Circular Básica Jurídica de la Superintendencia Financiera.

46 Numeral 3.6.3.3 de la Capítulo 2o Título VI de la Circular Básica Jurídica de la Superintendencia Financiera.

47 Corte Suprema de Justicia, Sala Civil, 29 de mayo de 2015, Exp. SC-6709-2015, MP. Jesús Vall de Rutén Ruíz.

48 Corte Suprema de Justicia, Sala Civil, 4 de marzo de 2016, Exp. n ${ }^{\circ}$ SC803-2016.

49 Articulo 3.6.3.5.7. de la Capítulo 2o Título VI de la Circular Básica Jurídica de la Superintendencia Financiera.

50 Corte Suprema de Justicia, Sala Civil, 27 de julio de 2015 Exp. SC-9618-2015, MP. Fernando Giraldo Gutiérrez.

51 Artículo 1066 del Código de Comercio. 
contributivas $^{52}$. En el seguro de vida grupo deudores el monto de la prima es globalmente inferior a aquella que existiría si se hubieran suscrito tantos contratos individuales como miembros hay en el grupo ${ }^{53}$. Ello se debe a que los gastos de gestión son inferiores para el asegurador que no tiene a cargo sino un solo contrato, frente al cual, la única intermediaria es la entidad bancaria suscriptora ${ }^{54}$.

No se puede sin embargo afirmar que esta mutación de la persona encargada del pago es extensiva a otros intervinientes al contrato de mutuo. Así, se juzgó por la Corte Suprema de Justicia en Sentencia de 23 de marzo de $2004^{55}$ según la cual el pago de la prima no le otorga la calidad de beneficiario al deudor solidario dentro del contrato de seguro, ni siquiera por vía de subrogación, puesto que en una tal situación no puede afirmarse que el deudor solidario hacía parte del contrato de seguro de vida grupo deudores. De otro lado, si la entidad bancaria recibe el pago de las primas sin informar al asegurado que no fue aceptado por la compañía de seguros para integrar el grupo, como fue destacado en la Aclaración de Voto de la Sentencia de 29 de mayo de $2015^{56}$ de la Corte Suprema de Justicia, el banco puede asumir la responsabilidad que este tipo de falta implica, siempre que en el contrato de mutuo se haya exigido la suscripción de un seguro de vida.

\section{FUNCIONAMIENTO DEL CONTRATO}

El contrato de seguro de vida grupo deudores tiene un esquema propio de operación que es diferente al de los contratos individuales tradicionales, lo cual requiere la observancia de unos requisitos específicos para la determinación del perímetro de cobertura (A). Sin embargo, se evidenció una necesidad de neutralizar los intereses en conflicto ya que los jueces encontraron una dificultad concreta en establecer una calificación jurídica del contrato. Ello motivó a la comunidad de juristas a discutir durante el último decenio las

52 Articulos 3.6.3.1.2 y 3.6.3.1.3 de la Capítulo $2^{\circ}$ Título VI de la Circular Básica Jurídica de la Superintendencia Financiera.

53 Assurance-vie (2017) Chapitre 1 Section 1, Le cours du contrat de groupe, ElNet Editions Législatives.

54 Ibid.

55 Corte Suprema de Justicia, Sala Civil, 23 de marzo de 2004, Exp. 14576, MP. Silvio Fernando Trejos Bueno.

56 Corte Suprema de Justicia, Sala Civil, 29 de mayo de 2015, Exp. SC-6709-2015, MP. Jesús Vall de Rutén Ruíz. 
diversas soluciones conceptuales que podrían establecerse para dar cuenta de la real naturaleza del contrato de seguro de vida grupo deudores (B).

\section{A. Operación del contrato}

La operación del contrato pasa por la necesaria delimitación previa del ámbito de la cobertura propio al contrato de seguro de vida grupo deudores (1), delimitación que permite que, ocurrido el siniestro, las garantías establecidas en el contrato marco, diseñadas por el asegurador y el banco, sean activadas en beneficio del asegurado-deudor, aunque pagadas directamente a la entidad bancaria (2).

\section{1. Ámbito de la garantia}

En el contrato de seguro de vida grupo deudores, el asegurador no otorga su garantía si previamente no se ha estipulado una demarcación de su espacio de intervención, esto es respecto de los límites temporales (a), así como respecto de los límites materiales del contrato de seguro de vida grupo deudores (b).

\section{a. Los limites temporales}

La interdependencia que existe entre el contrato de seguro y el contrato de mutuo explica que la duración de la garantía se extienda a lo largo de todo el periodo de reembolso del crédito. Así, se dice que el inclusión del asegurado en el grupo debe ser concomitante a la conclusión del contrato de préstamo, o más específicamente al momento de nacimiento de la obligación del deudor frente a la entidad crediticia ${ }^{57}$. Sin embargo, un periodo de carencia es en ocasiones establecido en los contratos colectivos del ramo vida respecto de la cobertura de incapacidad ${ }^{58}$. Al respecto, la Corte de Casación de Francia determinó que era labor de los jueces de instancia identificar si el periodo de carencia es excesivo, para lo cual pueden acudir a una comparación entre la duración del amparo y la duración específica del crédito ${ }^{59}$.

57 Kullman, J. et al. (2017) LamyLine, Lamy Assurances 2017, Chapitre 4, Assurances collectives, nro 4617, Wolters Kluwer France.

58 Courtieu G. (2005) Resp. civ. et assur., LexisNexis Jurisclasseur, Comm. 139.

59 Cass. 1re civ., 1er févr. 2005, no 03-18.795. 
De otro lado, le ley colombiana establece que el seguro termina para los asegurados sobrevivientes o incapacitados, en la fecha de fallecimiento o de la declaratoria total y permanente de la incapacidad ${ }^{60}$.

\section{b. El valor asegurado}

El asegurador es responsable únicamente de la suma asegurada ${ }^{61}$. El amparo del seguro de vida grupo deudores cubre el saldo de la deuda en el momento del siniestro ${ }^{62}$. Pero el saldo asegurado es el saldo insoluto, así como en los seguros que se pacten sobre un bien hipotecado el valor asegurado no sobrepasa el de la parte destructible del inmueble ${ }^{63}$. Por saldo insoluto se entiende el capital no pagado más los intereses corrientes calculados hasta la fecha del siniestro ${ }^{64}$. Aunque si el deudor incurrió en mora, el valor asegurado incluye los intereses moratorios y las primas del seguro no canceladas ${ }^{65}$. Sin embargo, para la Corte Suprema de Justicia en la Sentencia de 30 de junio de $2011^{66}$ una entidad crediticia podía concluir un seguro cuyo valor fue inferior al saldo insoluto de la deuda en el momento del siniestro. En efecto, bajo el principio indemnizatorio, el límite máximo frente al cual un banco podrá asegurarse es el saldo de la deuda, pero, concluyó la Corte, ello no obsta para que se fijen valores inferiores a éste. Esto se debe a que la ley colombiana permite que el seguro por cuenta ajena valga a favor del tomador hasta concurrencia de su interés en el contrato ${ }^{67}$. Sin embargo, ello no contradice que las partes, en ejercicio de la libertad contractual, acuerden valores adicionales dentro de la modalidad de una garantía facultativa, caso en el cual dichos montos serán en provecho del deudor.

La razón por la que se somete este tipo de contratos al imperio del principio indemnizatorio es que se clasifican tradicionalmente como seguros de daños. Así lo indicó la Sala Civil de la Corte Suprema de

\footnotetext{
60 Numeral 3.6.3.7 Capítulo $2^{\circ}$ Título VI de la Circular Básica Jurídica de la Superintendencia Financiera.

61 Artículos 1079 y 1089 del Código de Comercio.

62 Artículo 1044 del Código de Comercio.

63 Artículo 120 del Estatuto Orgánico del Sistema Financiero.

64 Numeral 3.6.3.7 Capítulo $2^{\circ}$ Título VI de la Circular Básica Jurídica de la Superintendencia Financiera.

65 Ibidem.

66 Corte Suprema de Justicia, Sala Civil, 30 de junio de 2011 Exp. 0019-01, MP. Edgardo Villamil Portilla.

67 Artículo 1042 del Código de Comercio.
} 
Justicia en Sentencia de 29 de mayo de $2015^{68}$ donde el monto asegurado fue el saldo no pagado, es decir un valor determinable, a diferencia de lo que ocurre en los seguros exclusivamente de personas, en los que por no ser de naturaleza indemnizatoria no tienen otro limite que el que libremente le asignen las partes. Los efectos de dicha clasificación no sufren modificación tratándose de los seguros reales ${ }^{69}$, puesto que la indemnización del contrato de seguro de vida grupo deudores hipotecario busca reemplazar la construcción siniestrada para que de esa manera surta los efectos que tenía la hipoteca frente al contrato de préstamo, y así la obligación de pago del crédito no se vea afectada con la ocurrencia del siniestro. Esta fue precisamente la posición de la Corte Suprema de Justicia en la Sentencia de 27 de julio de $2015^{70}$ donde mencionó que el seguro de incendio es un seguro resarcitorio que permite que se aseguren simultáneamente los diferentes intereses que pueden resultar afectados por la ocurrencia del riesgo y que concurren sobre un mismo inmueble, sin que la indemnización pueda llegar a exceder el valor que aquel tenía al momento del siniestro.

Es además la posición actual en otras jurisdicciones como Francia y Singapur. En Francia, la ley indica expresamente que el seguro colectivo es un seguro de daños si su objetivo no es la cobertura de riesgos relacionados con el empleo, que surgen de una convención colectiva o de la liberalidad del empleador ${ }^{71}$. En Singapur, la ley optó por aplicar a este tipo de contratos el limite indemnizatorio ${ }^{72}$ puesto que si bien el riesgo reposa sobre el deudor, es el capital otorgado en el préstamo, propiedad del banco, que es cubierto por la garantía ${ }^{73}$ y hasta concurrencia de este monto ${ }^{74}$.

68 Corte Suprema de Justicia, Sala Civil, 29 de mayo de 2015, Exp. SC-6709-2015, MP. Jesús Vall de Rutén Ruíz.

69 Ordóñez Ordóñez, A. (2001) El carácter Indemnizatorio del Seguro de Daños, Rev. Derecho Privado, n.3 (7).

70 Corte Suprema de Justicia, Sala Civil, 27 de julio de 2015 Exp. SC-9618-2015, MP. Fernando Giraldo Gutiérrez.

71 L. 129-1 du Code des assurances, Francia.

72 Section 2(1) of the Insurance (Valuation and Capital) Regulations 2004, Singapur.

73 Paragraph B18 in Appendix B of the International Financial Reporting Standards (IFRS 4) of the Companies (Accounting Standards) Regulations, Singapur.

74 Valerie Du ToitLow; GohLow Soen Yin; Lee Kiat Seng (2005) Insurance Law, No.24.1.8, Singapore Law, i-Law. 


\section{Realización del riesgo}

Si el siniestro consuma la pérdida o deterioro de la cosa asegurada, el asegurador responde del valor de la indemnización en los términos del contrato $^{75}$. Es decir, para la activación del amparo es necesario un siniestro bajo la noción que la póliza le otorga a este término y además que sea declarado según es exigido por la ley y el contrato, lo cual implica que la reparación no puede ser sino aquella que se establece en la póliza, de acuerdo a los limites allí expresamente estipulados. De esta forma, luego de la puesta en marcha del amparo con la declaración del siniestro (a) el pago de la indemnización tendrá lugar según los términos contractuales (b).

\section{a. La declaración del siniestro}

La ocurrencia del siniestro exige del asegurado la satisfacción de su obligación de dar aviso al asegurador ${ }^{76}$ so pena de que éste descuente de la indemnización el monto de los perjuicios que se le hubieren causado con la declaración tardía o incluso que se rechace en su integralidad la cobertura $^{77}$. Sobre el particular se ha planteado la pregunta de cuál es el momento para dar aviso del siniestro (i) así como de quién tiene a su cargo cumplir con la declaración del siniestro (ii).

i. El punto de partida del término para dar aviso del siniestro es desde el momento en el que el asegurado (o el tomador) tuvieron o debieron haber tenido conocimiento del siniestro ${ }^{78}$. Si el siniestro es la materialización del riesgo asegurado ${ }^{79}$, en las garantías que cubren el patrimonio de las entidades bancarias el siniestro se constituye desde el impago, esto es, según los términos que fueron establecidos en el contrato de préstamo. Así se interpretó en el Laudo Arbitral Nubiola Colombia Pigmentos S.A. contra La Compañía Mundial de Seguros S.A., de 21 de Junio de $2.010^{80}$ según el cual, el siniestro

75 Artículo 1073 del Código de Comercio.

76 Artículo 1075 del Código de Comercio.

77 Artículo 1078 del Código de Comercio.

78 Por ejemplo, el artículo L113-2 del Código de Comercio francés no impuso un término para dar aviso del siniestro, pero mencionó que dicho deber tiene lugar desde que el asegurado tuvo conocimiento del siniestro.

79 Artículo 1072 del Código de Comercio

80 Nubiola Colombia Pigmentos S.A. contra La Compañía Mundial de Seguros S.A., 21 de Junio de 2.010, Árbitro único Ricardo Vélez Ochoa. 
tuvo ocurrencia desde el momento en que hubo omisión de la deuda que estaba vencida, lo que quiere decir que la materialización del riesgo tuvo lugar cuando no se pagó el préstamo en el lugar, fecha y divisa especificados en el contrato. Es entonces a partir de éste momento en que debe darse aviso del siniestro, contándose para ello con un plazo mínimo ${ }^{81}$ que puede ser aumentado pero no reducido por las partes. El hecho de que el momento a partir del cual comienza a correr el término para dar aviso al asegurador sobre la ocurrencia del siniestro es específicamente la ausencia de pago en la fecha establecida en el contrato de mutuo subyacente ha sido confirmado en otras jurisdicciones, como en Singapur donde la High Court determinó en la Decisión TKM (Singapore) Pte Ltd v Export Credit Insurance Corp of Singapore Ltd [1992] ${ }^{82}$ que el deudor tenía una expectativa legítima de ser indemnizado desde el momento de haber dado noticia del siniestro al asegurador, lo cual hubiera evitado tener que acceder a otros instrumentos para cumplir con las amortizaciones retrasadas con la entidad prestamista.

De otro lado, tratándose del riesgo de invalidez, la Delegatura para Funciones Jurisdiccionales de la Superintendencia Financiera en Sentencia de 11 de septiembre de $2015^{83}$ determinó que la configuración del siniestro tiene lugar, sea en la fecha de estructuración de la pérdida de capacidad laboral, o sea en la fecha de calificación de la misma. Puede decirse entonces, como se dilucidó en un texto, que la fecha de configuración del riesgo es aquella que es más beneficiosa para el asegurado ${ }^{84}$.

ii. Tratándose de un seguro colectivo, surge la pregunta de quién es la persona que tiene a su cargo declarar la ocurrencia del siniestro, esto es, si dicha carga corresponde al asegurado o al tomador. En Sentencia de 27 de julio de $2015^{85}$ la Corte Suprema de Justicia determinó

81 La ley otorga un plazo mínimo de tres días para dar aviso del siniestro, artículo 1075 del Código de Comercio.

82 TKM (Singapore) Pte Ltd v Export Credit Insurance Corp of Singapore Ltd [1992] 2 SLR(R) 858.

83 Delegatura para Funciones Jurisdiccionales de la Superintendencia Financiera, Sentencia 2014-1167, sep. $11 / 15$.

84 Fecha de calificación de pérdida de capacidad laboral estructura el siniestro en seguro que ampara créditos (2016) Ambito Juridico, Multilegis, 27 de mayo del 2016.

85 Corte Suprema de Justicia, Sala Civil, 27 de julio de 2015 Exp. SC-9618-2015, MP. Fernando Giraldo Gutiérrez. 
que el deudor conocía sus obligaciones en su calidad de asegurado puesto que, de un lado, le fue enviado el certificado individual del seguro de vida grupo deudores, y que, de otro lado, el gravamen que se constituyó en el inmueble imponía al hipotecante la obligación de adquirir un contrato de seguro. Por ello, concluyó la Corte, la declaración del siniestro estaba a cargo del deudor, mientras que perseguir el seguro no era sino optativo para el banco-tomador, puesto que, a pesar del desastre, el bien hipotecado seguía siendo suficiente para cubrir la deuda.

\section{b. Pago de la prestación}

La responsabilidad del asegurador no irá más allá del monto asegurado en el momento del siniestro ${ }^{86}$. Así, a cargo del asegurador está el saldo insoluto de la deuda de manera que al realizar el pago el asegurador, por efecto de la estipulación por otro, se libera al deudor de la obligación adquirida con la entidad crediticia ${ }^{87}$. Pero este efecto extintivo se limita únicamente al monto efectivamente pagado por el asegurador, como se decidió por la Corte de Casación de Francia ${ }^{88}$, al decidir que un pago parcial de la deuda por el asegurador del codeudor solidario que decedió, no exonera más allá de dicho monto, de manera que solo los herederos son desinteresados por la entidad crediticia. Este principio extintivo que está limitado al monto efectivamente pagado por el asegurador, fue aplicado por la Corte Suprema de Justicia de Colombia en la Sentencia de 23 de marzo de $2004^{89}$ según la cual, el banco puede perseguir la satisfacción de la deuda en contra del deudor solidario, en ausencia de un efecto extintivo total de la deuda debida a la objeción de la compañía de seguros. Es esta una posición clásica respecto de éste tipo de situaciones en los contratos de seguro de vida grupo deudores, porque hasta tanto no se logre demostrar que el asegurador es responsable del rembolso del crédito, el deudor permanece a cargo del pago de las amortizaciones, como se decidió en Francia por la Corte de Casación ${ }^{90}$.

\footnotetext{
86 Artículo 1079 del Código de Comercio.

87 Kullman, J. et al. (2017) LamyLine, Lamy Assurances 2017, Chapitre 4, Assurances collectives, n. 4620, Mise en oeuvre de la garantie, Wolters Kluwer France.

88 Cass. 1re civ., 12 mars 2002, no 00-21.271.

89 Corte Suprema de Justicia, Sala Civil, 23 de marzo de 2004, Exp. 14576, MP. Silvio Fernando Trejos Bueno.

90 Cass. 1re civ., 9 juin 1998, no 96-13.708.
} 


\section{B. Efectos del contrato}

Los seguros colectivos surgieron como un mecanismo de cobertura de riesgos adicional a las soluciones tradicionales de la seguridad social. Inicialmente presentados como una modalidad de protección patronal en profesiones reglamentadas ${ }^{91}$, posteriormente fueron comercializados por las empresas de seguros utilizando el esquema colectivo como una medida de disminución de costos operativos, lo que en definitiva posibilitó su distribución en masa ${ }^{92}$. Si en un principio la labor jurisprudencial se concentró en definir cuáles son las facultades y límites de las partes intervinientes en el contrato de seguro vida grupo deudores (1), la necesaria de protección de los asegurados ${ }^{93}$, propia del derecho de seguros, reclamó la creación de teorías jurídicas para explicar su funcionamiento y solventar sus problemas estructurales (2).

\section{Facultades y limites de las partes}

El análisis jurisprudencial y doctrinal se ha concentrado no solo en la responsabilidad de la entidad de crédito que se declara toda vez que se desconoce una prestación que nace del contrato o de un deber de origen legal y que a la par causó un daño al reclamante (a), pero además respecto de los derechos que le son propios a los deudores-adherentes al contrato de seguro de vida grupo deudores (b).

\section{a. Responsabilidad civil del banco}

A la par que la Corte Suprema de Justicia ha estudiado la responsabilidad de la entidad crediticia frente a situaciones en las cuales los usuarios se han estimado víctimas del desconocimiento de los deberes de información que les son propios a los bancos dentro de los seguros de vida colectivos,

91 Bigot, J. (2016) Problématique des assurances collectives de dommages, Revue générale du droit des assurances, Lextenso - 01/10/2016 - nº 10 - page 459, RGA113v1.

92 Como lo explica el profesor Bigot: "al reagrupar todos los riesgos, o al menos un grupo importante de los miembros de una profesión, los seguros colectivos permiten la constitución de mutualidades relativamente homogéneas de manera que el seguro podrá ser establecido a condiciones técnicas y tarifarias ventajosas" (traducción libre) en: Bigot, J. (2016) Problématique des assurances collectives de dommages, Revue générale du droit des assurances, Lextenso - 01/10/2016 - n 10 - page 459, RGA113v1.

93 Protección que no se limita al asegurado consumidor o no profesional, Bentin-Liaras, M. (2014) La protection par le droit des assurances, Revue générale du droit des assurances, Lextenso - 01/05/2014 - $\mathrm{n}^{\circ} 05$, RGA110u7. 
la Sala Civil también ha analizado las cargas que le son inherentes a los otros intervinientes al seguro colectivo.

En la Sentencia de 30 de junio de $2011^{94}$ la Corte Suprema de Justicia determinó que, a pesar de que la entidad crediticia se encontrase en una posición dominante respecto del deudor, es a éste al que le compete la carga de la prueba de la demostración de un comportamiento reprochable del banco. Así, bajo las circunstancias de dicho caso, consideró la Sala Civil que no había un título de condena en contra de la entidad crediticia por el hecho de que el valor asegurado haya sido inferior al monto de la deuda. En efecto, al habérsele comunicado el certificado individual de cobertura y la copia de las condiciones del contrato, junto con la estipulación de la tarifa aplicable, el banco cumplió con la obligación de información que le es propia. Explicó la Sala Civil que existe así una obligación de información impuesta a las entidades de crédito, la cual es la contraparte a la posición dominante del banco y al hecho de que se trata de contratos típicamente de adhesión. Pero rechazó sin embargo que existiera responsabilidad contractual de la entidad crediticia al no haber existido un comportamiento censurable por haber decidido tomar el seguro por un valor inferior al monto de la deuda al momento del siniestro.

En la Sentencia de 27 de julio de $2015^{95}$ realizó la Corte Suprema un análisis de las obligaciones que son inherentes a las partes del contrato de seguro, específicamente la conservación del estado del riesgo a cargo del deudor asegurado. En dicho caso, al momento de declarar el siniestro, se descubrió una situación de infraseguro causada por las variaciones de precios en el mercado inmobiliario. Consideró la Sala Civil que, si bien el Banco resultó ser el único beneficiario de la indemnización como consecuencia del infraseguro, esa situación no le era imputable, puesto que deber el de mantener asegurado el bien hipotecado por el valor comercial de su parte destructible es una carga que corre por cuenta del deudor, así el acreedor haya contado con la autorización para contratar el seguro y asumir por sí mismo los pagos de la prima periódica.

94 Corte Suprema de Justicia, Sala Civil, 30 de junio de 2011 Exp. 0019-01, MP. Edgardo Villamil Portilla.

95 Corte Suprema de Justicia, Sala Civil, 27 de julio de 2015 Exp. SC-9618-2015, MP. Fernando Giraldo Gutiérrez. 
En la Sentencia de 5 de mayo de $2014^{96}$ la Corte Suprema de Justicia procedió a realizar un análisis de la responsabilidad de la entidad crediticia a través de régimen de responsabilidad extracontractual, específicamente sobre la efectividad de la integración del deudor al grupo de asegurados. En este litigio la aseguradora aceptó haber recibido las primas, lo que implicó que el deudor estaba bajo la creencia de haber adquirido el seguro. Sin embargo, se rechazó la integración del deudor al grupo de asegurados por el no cumplimiento de los requisitos exigidos. Este rechazo solo fue informado al acreedor-tomador, sin éste por su parte se preocupara por comunicárselo al deudor. La Corte sancionó este comportamiento de la entidad bancaria pero rechazó la pretensión sobre la responsabilidad contractual, sustituyendo los motivos del fallo. Para la Sala Civil, de un lado, los perjuicios no surgieron del vínculo del contrato de mutuo existente entre el banco y el deudor, ni tampoco de la relación de la entidad bancaria y la aseguradora, respecto de la cual consideró al deudor como un tercero. Siendo entonces externa a dichos vínculos, la responsabilidad que era predicable de la entidad crediticia era la extracontractual y reconoció entonces los perjuicios materiales y morales derivados del comportamiento del banco.

La Corte Suprema tuvo además otra oportunidad de analizar el tema de la efectividad de la suscripción del contrato de seguro y la responsabilidad de la entidad bancaria. Una cláusula del mutuo exigía la suscripción de un contrato de seguro o en su defecto la constitución de una garantía adicional. En dicho litigio, resuelto por la Corte en la Sentencia de 28 de mayo de $2015^{97}$, consideró la Sala que en dicha ocasión no podía deducirse de ésta cláusula una obligación del banco a obtener de la compañía de seguros la integración cierta del deudor en el grupo de asegurados. Al respecto, la Corte tuvo en cuenta que la objeción de la cobertura por la compañía de seguros se debió a una circunstancia externa al banco, esto es, que el deudor no podía tener la calidad de asegurado por su edad. No declaró entonces la responsabilidad del banco porque la falta de suscripción de un contrato de seguro de vida no puede ser imputable a la entidad crediticia, la cual no se comprometió a obtener en benefi-

96 Corte Suprema de Justicia, Sala Civil, 5 de mayo de 2014 Exp. SC-5189-2014, MP. Margarita Cabello Blanco.

97 Corte Suprema de Justicia, Sala Civil, 28 de mayo de 2015, Exp. SC-6709-2015, MP. Jesús Vall de Rutén Ruíz. 
cio de su crédito un tal amparo. Sin embargo, en la aclaración de voto expresada por un Magistrado ${ }^{98}$, se precisó que a pesar de que, bajo las expresas condiciones del caso sometido a la jurisdicción, no se demostró que la suscripción de un seguro fuere obligatorio para las partes, cuando un acuerdo en este sentido esté claramente demostrado, la efectividad de la suscripción deviene en una obligación para la entidad crediticia, de manera que ésta no puede liberarse de dicha carga a su antojo. Pero más aún, en el Salvamento de Voto de la misma sentencia, dos Magistrados ${ }^{99}$ expresaron que el banco tomador estaba en posibilidad de cumplir con la obligación de informar a la aseguradora de la edad del deudor. Al no hacerlo desconoció la obligación que su calidad de tomadora le impone y por ello debió estar llamada a indemnizar los perjuicios que su incumplimiento acarreó. Además de ello, expresaron los Magistrados, puesto que el banco no informó de la edad del adherente y a pesar de ello la aseguradora recibió las primas, se entendía que las partes consintieron en celebrar un contrato bajo dichas condiciones.

Las discrepancias que al interior de la Corte Suprema generó la decisión de la 28 de mayo de 2015 explican en cierta medida el desequilibrio existente respecto de las entidades crediticias que de un lado exigen del usuario la suscripción de un contrato de seguro, pero de otro, con su comportamiento, pueden llegar a impedir una operación esperada del contrato. Buscando resolver este tipo de problemas, otras jurisdicciones han creado en cabeza de las entidades bancarias unas obligaciones de información que se han configurado con el paso del tiempo hasta la imposición de un deber de explicación y asesoría al usuario referido substancialmente a las condiciones de funcionamiento del contrato de seguro de grupo ${ }^{100}$. En Francia, se habla actualmente de una obligación contractual de la entidad bancaria de explicación al deudor sobre la 'adéquation'101 de los riesgos cubiertos a la situación personal del solicitante. En Singapur, una obligación de información especial se establece en favor de los consumidores de créditos que tienen que ser instruidos sobre todo 'material fact', toda información relevante que pueda influir

\footnotetext{
98 Álvaro Fernando García Restrepo.

99 Ariel Salazar Ramírez y Luis Armando Tolosa Villabona.

100 Kullman, J. et al. (2017) LamyLine, Lamy Assurances 2017, n. 4612-1- Devoir de conseil, devoir d'éclairer Wolters Kluwer France.

101 Cass. ass. plén., 2 mars 2007, no 06 $\square 15.267$.
} 
en su decisión de adquirir el servicio ${ }^{102}$. Sin embargo, como fue decidido en Pender Development Pte Ltd and another v Chesney Real Estate Group $L L P^{103}$, para la High Court de Singapur, cuando se trata de personas jurídicas, no puede solicitarse la rectificación de una información que tuvo efectos en el funcionamiento del contrato de seguro, más aun si un error en el establecimiento del contrato de crédito subyacente no fue informado por la tomadora-acreedora a la compañía aseguradora ${ }^{104}$.

\section{b. Derechos del deudor}

El análisis de los derechos del usuario, deudor o consumidor en el contrato de seguro de vida grupo deudores se ha centrado en el derecho de libertad contractual y en sus ámbitos de respeto de los deberes de información y del derecho a decidir la suscripción del contrato. El asegurador tiene la obligación de informarle al candidato al crédito que tiene derecho a escoger la entidad aseguradora con la cual desea suscribir un contrato de seguro vida deudores, o si no es el caso informar que tiene derecho a escoger un asegurador diferente al que es ofertado o anunciado por la entidad bancaria ${ }^{105}$. Es precisamente frente a este segundo caso que la en la Sentencia de 30 de junio de 2011 ${ }^{106}$, la Corte Suprema de Justicia recordó que el ciudadano contratante del mutuo tiene derecho a escoger la compañía de seguros con la cual asegurar su deuda, aunque el banco haya contratado estos servicios directamente con una compañía de seguros de su escogencia. Valga mencionar además que en esta jurisprudencia se mencionó que, una vez integrado el deudor en el grupo de asegurados, y ocurrido el siniestro, no podrá la entidad bancaria elegir si acudir a la prenda general, sin activar la póliza pues en tal caso, consideró la Corte, se haría nugatoria la protección del seguro.

La información del deudor se puede ver plasmada en la entrega del certificado individual de cobertura y la copia de las condiciones del con-

102 Paragraphe n. 20, Second Schedule, Part 1, Consumer Protection (Fair Trading) Act (Chapter 52A), Singapur.

103 Pender Development Pte Ltd and another v Chesney Real Estate Group LLP [2009] 3 SLR(R) 1063; [2009] SGHC 126.

104 Lee Pey Woan; Tham Chee Ho (2009), Contract Law 10 SAL Ann Rev 194 Singapore Academy of Law Annual Review.

105 Numeral 2.1.1 literal g) del Capítulo $2^{\circ}$ del Título III de la Circular Básica Jurídica de la Superintendencia.

106 Corte Suprema de Justicia, Sala Civil, 30 de junio de 2011 Exp. 0019-01, MP. Edgardo Villamil Portilla. 
trato de seguro. Por ello es que se ha considerado que el instrumento del seguro de grupo, que es el contrato de seguro suscrito entre aseguradora y suscriptor, se ve reemplazado por la expedición de éstos documentos de información ${ }^{107}$. En efecto, si bien la transmisión de dichos documentos representa la ejecución de una carga propia a la compañía aseguradora, el cumplimiento del deber de información es propio a la entidad bancaria, quien debe responder por un deber de aclaración y explicación de las garantías, obligación de origen pretoriano que le es impuesta debido a su situación de suscriptor, de la misma manera en que se ha concebido este deber en los ordenamientos de Francia y Singapur ${ }^{108}$.

Esta libertad de escogencia, reconocida por la jurisprudencia y plasmada en la ley de manera gradual, encuentra su límite respecto del tipo de garantías requeridas para el préstamo. En efecto, el contrato externo con una aseguradora que haya sido escogida por el deudor, como fue considerado por la Corte Suprema de Justicia en la Sentencia de 28 de mayo de $2015^{109}$ tiene que contener al menos las mismas condiciones plasmadas en el pliego ofrecido por el banco. Pero para que el candidato pueda conocer cuáles son los requisitos exigidos y le sea entonces posible escoger entre dos opciones propuestas, le debe ser expedido un certificado individual, además de las condiciones del contrato de seguro ofrecido por el asegurador vinculado a la entidad crediticia, de manera que éste pueda contar con la debida información sobre el contenido y el alcance de la póliza de seguro requerida para otorgar el crédito. Es de esta forma como el derecho de información se establece como una circunstancia previa al ejercicio de la libertad contractual en sus dos esferas, de no negociación o de negociación con otra entidad.

Como se mencionó, Colombia no está exenta de la tendencia que interpreta el rol que juega el suscriptor en los seguros colectivos de manera rigurosa, dentro de una propensión internacional hacia la protección

107 Astegiano-La Rizza, A. et Abravanel-Jolly, S. (2017) De quelques rappels de règles quant à l'opposabilité des exceptions contractuelles en assurance de groupe, Bulletin Juridique des Assurances BJDA, n. 59 mars-avril 2017.

108 En Francia, Cass. com., 1er déc. 2015, n 14-22134. En Singapur, Paragraphe n. 20, Second Schedule, Part 1, Consumer Protection (Fair Trading) Act (Chapter 52A).

109 Corte Suprema de Justicia, Sala Civil, 28 de mayo de 2015, Exp. SC-6709-2015, MP. Jesús Vall de Rutén Ruíz. 
del usuario. Se tiende entonces a exigir del banco un comportamiento de aclaración o explicación hacia el deudor ${ }^{110}$ sobre la adaptabilidad del contrato propuesto a la situación personal del asegurado ${ }^{111}$, llegándose incluso a considerar que la transmisión del documento de información no es suficiente para satisfacer a esta obligación ${ }^{112}$, puesto que para la Corte de Casación en el caso de Francia, los deudores que adhieren a un contrato de seguro de grupo propuesto por un establecimiento de crédito son una categoría de asegurados que merecen una protección jurídica particular ${ }^{113}$, específicamente por la vulnerabilidad del individuo deudor-asegurado frente a dos personas jurídicas diferentes que integran el contrato, de manera que esta vulnerabilidad se convierte en la razón que justifica la imposiciones de las obligaciones de aclarar y explicar ${ }^{114}$.

\section{El esquema contractual}

Los seguros colectivos han generado gran dificultad de interpretación porque, como se ha indicado, el derecho vigente a través del cual se deciden las controversias de estos fue concebido únicamente para los contratos individuales, de manera que su transposición a los contratos colectivos es dificultosa ${ }^{115}$. Adicional a ello se trata de contratos de seguro distribuidos como un producto accesorio al ofrecido por la entidad financiera ${ }^{116}$, lo que perturba el entendimiento sobre el régimen que le es propio, tratándose de un contrato adjunto o affinitaire. Estas dos situaciones han provocado la insistencia de 'batallones de litigantes' ${ }^{117}$

110 Como es actualmente lo ordena el artículo 9 de la Ley 1328 de 2009, que exige que la entidad financiera ( adecuada comparación de las distintas opciones ofrecidas en el mercado.

111 Kullman, J. et al. (2017) LamyLine, Lamy Assurances 2017, Wolters Kluwer France, n4612-1Devoir de conseil, devoir d'éclairer.

112 Cass. ass. plén., 2 mars 2007, no 06-15.267.

113 Nicolas, V. (2015) Le banquier, mandataire de l'assureur dans les assurances de groupe?, L'Essentiel de droit des assurances, Lextenso, 16/09/2015 - nº 08 - page 1, EDAS2015111.

114 Kullman, J. et al. (2017) LamyLine, Lamy Assurances 2017, Wolters Kluwer France, n²4612-1Devoir de conseil, devoir d'éclairer, 2- Evolution.

115 Bigot, J. (2016) Problématique des assurances collectives de dommages, Revue générale du droit des assurances, Lextenso - 01/10/2016 - n 10 - page 459, RGA113v1.

116 Astegiano-La Rizza, A. et Abravanel-Jolly, S. (2014) La reconnaissance législative de l'assurance collective de dommages, Bulletin Juridique des Assurances BJDA, n. 35 mars-avril 2014.

117 Kullman, J. (2015) Assurances liées à un crédit et TEG : comment piéger l'emprunteur, Revue générale du droit des assurances, Lextenso, 01/01/2015 - nº 01 - page 7, RGA111t3. 
que llegan a las cortes de casación buscando la distinción de roles entre las entidades intervinientes y el reconocimiento de los derechos de los deudores, usuarios o consumidores. En respuesta, los tribunales han analizado los contratos desde dos teorías divergentes sin que se reduzca plenamente el margen conflictual (a) lo cual ha generado como respuesta la necesidad de estudiar una tercera interpretación que pueda solventar los problemas presentados por las dos anteriores doctrinas (b).

\section{a. Un contrato único o contratos sucesivos}

La primera teoría afirma que el negocio jurídico del seguro de grupo se basa en un contrato único establecido entre el asegurador y el banco tomador. Según esta concepción unitaria, el cliente deudor es beneficiario del amparo de seguro, no porque él esté vinculado al asegurador en una relación contractual directa, sino como efecto de una estipulación en favor de tercero ${ }^{118}$. Esta concepción, que ya es clásica en algunos ordenamientos, permite darle la calidad de parte únicamente a la persona que negoció el contrato, específicamente al banco y a la aseguradora. Entonces, en este esquema el beneficiario de la estipulación es un tercero que no es parte del contrato ${ }^{119}$. Un único contrato existe pues entre la entidad crediticia y la aseguradora, dentro del cual múltiples estipulaciones a favor de terceros se establecen por el banco-tomador. En este esquema no hay selección individual de los asegurados ${ }^{120}$ y el pago de la prima por los deudores no desnaturaliza ${ }^{121}$ el régimen que le es aplicable puesto que una estipulación por otro con imposición de cargas es posible desde que el beneficiario la acepte expresamente ${ }^{122}$.

118 Kullman, J. et al. (2017) LamyLine, Lamy Assurances 2017, Chapitre 4, Assurances collectives, n. 4625- Règles applicables aux adhésions des contrats d'assurance de groupe : article L. 113-12 du Code des assurances?

119 Astegiano-La Rizza, A. et Abravanel-Jolly, S. (2011) A la recherche de la juste qualification des liens unissant assureur, souscripteur et adhérents en assurance de groupe, Bulletin Juridique des Assurances BJDA, n 19 Janvier Fevrier 2011.

120 Por ello es que bajo el parágrafo segundo del artículo 1064 del Código de Comercio Colombiano, tratándose de una comunidad de personas e intereses que permite considerarlos como un solo riesgo a la luz de la técnica aseguradora, las sanciones de reticencia solo se aplican al acuerdo entre el asegurador y el banco-tomador.

121 Bigot, J. (2016) Problématique des assurances collectives de dommages, Revue générale du droit des assurances, Lextenso - 01/10/2016 - n 10 - page 459, RGA113v1.

122 Artículo 1141 del Código de Comercio. 
Su contendora es la teoría del contrato difuso de seguro de grupo. En esta teoría la adhesión al seguro colectivo implica la creación de un negocio jurídico directo entre el asegurador y el deudor-asegurado. Esta concepción dualista evidencia otra relación contractual frente a la cual cada parte interviniente es reconocida ${ }^{123}$ viz el deudor. Sin embargo, este punto de vista no concibe la operación jurídica del seguro en su globalidad, sino que se concentra en los diferentes contratos que la componen ${ }^{124}$ fragmentando sus efectos. Por ello es que un contrato marco surge del acuerdo entre la entidad bancaria y el asegurador, pero al mismo tiempo varios contratos individuales son establecidos con cada adherente al grupo, materializados por su solicitud de integración, cuya aceptación se concreta en el certificado individual. Así, el contrato marco es desarrollado por contratos subsiguientes y el negocio vinculante es únicamente existente entre el asegurado-deudor y la aseguradora. En este esquema, el banco, a pesar de haber acordado las condiciones generales del negocio jurídico, es un tercero al contrato que se crea entre el asegurado-deudor y la aseguradora ${ }^{125}$. En la teoría difusa del contrato de seguro grupo la existencia de derechos de los adherentes es justificada por los contratos de aplicación que son oponibles directamente contra del asegurador. Pero estos derechos encuentran su límite en las cláusulas del contrato marco ${ }^{126}$ ya que las excepciones, limitaciones y exclusiones de garantía son oponibles a los asegurados ${ }^{127}$.

Si de la interpretación de algunos artículos de nuestro Estatuto Comercial podría tomarse partido por una de las dos teorías, nuestra Corte Suprema de Justicia no ha consagrado de manera expresa ninguna de dichas concepciones. Sin embargo, de la lectura de las consideraciones ratio y dicta de las decisiones estudiadas se puede concluir que la Sala Civil ha utilizado una u otra de las teorías para resolver los diferentes casos some-

123 Op. Cit. Bigot.

124 Ibidem.

125 Astegiano-La Rizza, A. et Abravanel-Jolly, S. (2011) A la recherche de la juste qualification des liens unissant assureur, souscripteur et adhérents en assurance de groupe, Bulletin Juridique des Assurances BJDA, nº 19 Janvier Fevrier 2011.

126 Bigot, J. (2016) Problématique des assurances collectives de dommages, Revue générale du droit des assurances, Lextenso - 01/10/2016 - nº 10 - page 459, RGA113v1.

127 Siguiendo este análisis podría citarse el parágrafo primero del artículo 1064 del Código de Comercio Colombiano que permite la aplicación de las sanciones de la reticencia frente a cada vínculo creado entre el asegurador y las personas e intereses identificados. 
tidos a su jurisdicción. Si dicha conducta es deseable, sobre todo frente a la necesidad de protección del asegurado sin llegar a desnaturalizar el contrato colectivo, consideramos que ello genera incertidumbre sobre la política de la Corte frene a la discrecionalidad con que cuentan los jueces de instancia para determinar la calificación jurídica del vínculo que une las partes en el contrato de seguro de vida grupo deudores. Se puede llegar entonces a desnaturalizar la función de la casación al permitirse la creación de diferentes regiones normativas dentro del territorio nacional según la posición que asuma cada Tribunal Superior. Ello no es deseable pues contraría la seguridad jurídica y permite en cierta medida una elección del foro, propio a algunos litigantes inescrupulosos. Veremos sucintamente a continuación como la Corte ha utilizado ambas teorías, de forma explícita o implícita, para resolver los casos sometidos a su jurisdicción.

En la Sentencia de la Corte Suprema de Justicia de 25 de mayo de $2005^{128}$ se analizó el vínculo negocial como un contrato existente entre el banco y la aseguradora, seguido de estipulaciones sucesivas a favor de los deudores. En dicha ocasión la Sala Civil consideró que los demandantes, causahabientes del deudor, al saldar la deuda adquirieron la calidad de beneficiarios a título oneroso, porque esa era precisamente la posición del banco en el contrato de seguro, que no es lo mismo a que fueran beneficiarios "directos" del citado seguro de vida grupo deudores.

Esta concepción unitaria fue igualmente seguida en la Sentencia de 6 de julio de $2007^{129}$ según la cual el seguro de vida grupo deudores es una modalidad del seguro de personas que permite a un solo tomador asegurar un número indeterminado de adherentes. En dicha oportunidad, manifestó la Corte que si bien el tomador se encuentra obligado a cumplir con las obligaciones inherentes a tal calidad, razonó que in fine la sanción de la reticencia no le es aplicable al asegurado, es decir la omisión en la declaración de riesgos ${ }^{130}$.

128 Corte Suprema de Justicia, Sala Civil, 25 de mayo de 2005, Exp. C-7198, MP. Jaime Alberto Arrubla Paucar.

129 Corte Suprema de Justicia, Sala Civil, 6 de julio de 2007 Exp. 0359-01, MP. Carlos Ignacio Jaramillo Jaramillo.

130 Sin embargo, en dicha oportunidad la Corte examinó el caso desde la prohibición del artículo 1060 del Código de Comercio sobre el deber de mantener el estado del riesgo sin que hubiese tenido en cuenta que el artículo 1064 permite la aplicación de las sanciones de la reticencia frente a cada vínculo creado entre el asegurador y el asegurado, por la naturaleza de este vínculo. 
Empero, esta tendencia fue morigerada por la Sentencia de 30 de junio de $2011^{131}$ en la cual se falló teniendo en cuenta los efectos jurídicos de un vínculo existente entre la aseguradora y el deudor, virando entonces hacia una teoría difusa del contrato de seguro grupo. Encontró la Corte que existe en el deudor un interés preponderante en la prestación prometida en el contrato y por esta razón es necesaria su aquiescencia a las condiciones del seguro reflejada en una solicitud individual de ingreso. Sin embargo, no encontró la Sala Civil un fundamento jurídico suficiente que hiciera necesaria su protección, dándole de ésta forma un rol de contratante pleno frente al cual no existe un deber particular de información en lo referente al monto asegurado por parte del banco. Así, la intervención de la entidad crediticia se limitó al establecimiento del acuerdo tipo con la aseguradora, sin que de ello se desprendiera un deber de información sobre los requisitos de cobertura.

Esta posición fue sin embargo contenida en la Decisión de 5 de mayo de $2014{ }^{132}$ que se podría catalogar como un retorno a la teoría unitaria. En las circunstancias de dicho caso, se estableció que el contrato de seguro nunca existió porque el deudor no podía integrar el grupo de asegurados. Las partes pensaron que la no admisión del deudor en el grupo de asegurados solo debía notificársele al banco. Éste, por su parte, nunca informó a su cliente del rechazo de la aseguradora, a pesar de que el deudor siguió cancelando las primas. Así, un análisis estrictamente bilateral (banco-asegurador) predominó, de manera que el deudor, y más concretamente su consentimiento, no jugaron rol alguno. Esta interpretación fue seguida por el Tribunal Superior, frente a lo cual la Sala Civil no expresó censura, a pesar de que la entidad crediticia sucumbió en el juicio por violación de una cláusula del contrato de mutuo.

En la Sentencia de 28 de mayo de $2015^{133}$, la Sala Civil no encontró un fundamento legal o contractual para imputar a la entidad crediticia la obligación de verificar la integración del deudor al grupo de asegura-

131 Corte Suprema de Justicia, Sala Civil, 30 de junio de 2011 Exp. 0019-01, MP. Edgardo Villamil Portilla.

132 Corte Suprema de Justicia, Sala Civil, 5 de mayo de 2014 Exp. SC-5189-2014, MP. Margarita Cabello Blanco.

133 Corte Suprema de Justicia, Sala Civil, 28 de mayo de 2015, Exp. SC-6709-2015, MP. Jesús Vall de Rutén Ruíz. 
dos, es decir una de las obligaciones inherentes a las partes del contrato de seguro. De esta forma, atribuyó al deudor el deber de verificar por sí mismo la aceptación del asegurador, haciendo pesar en él las cargas que le son propias a un contratante del seguro. A pesar de ello, una voz de disidencia ${ }^{134}$ se elevó dentro de la misma Corte para sostener que el banco dirige un conglomerado de contratos de mutuo y de seguro, de manera que éste regenta todo el sistema contractual y por lo tanto asume las obligaciones de información a cargo de la aseguradora. Por ello, según los Magistrados, es el banco quien se apropia del deber de constatar que las personas que incluye en la lista del grupo de deudores cumplan con los requisitos para ser asegurados.

Posteriormente, en la Sentencia de 27 de julio de $2015^{135}$ la Corte supeditó la activación del amparo a la exclusiva intervención del deudorasegurado, el cual, estando en conocimiento de la existencia del contrato de seguro, tenía una perspectiva de provecho con la reclamación de la garantía. Es de esta manera que el deudor estaba legitimado para acudir directamente ante la aseguradora y obtener reparación en los términos del contrato, independientemente de la pasividad que frente a la declaración del siniestro mostrara la entidad bancaria. Teniendo a cargo el deudor las obligaciones que surgen del contrato de seguro, se puede afirmar que la Corte realizó un análisis desde la teoría difusa que exige el reconocimiento de un contrato de seguro entre la compañía y el deudor, más allá de la operación global contratada con la entidad crediticia.

Ulteriormente, en la Sentencia de 14 de marzo de $2017^{136}$ la Corte desarrolló el mismo análisis al imponer al asegurado la integralidad de las obligaciones que le caben en su calidad de adquirente del seguro. El deudor había solicitado la condena de la entidad bancaria que no le informó de la decisión de no continuar pagando la prima de seguro de vida que fungía como garantía adicional de su deuda. Adujo como perjuicio la pérdida de la oportunidad de retomar el pago de las primas,

134 Salvamento de Voto de Ariel Salazar Ramírez y Luis Armando Tolosa Villabona en la Sentencia de la Corte Suprema de Justicia, Sala Civil, 28 de mayo de 2015, Exp. SC-6709-2015, MP. Jesús Vall de Rutén Ruíz.

135 Corte Suprema de Justicia, Sala Civil, 27 de julio de 2015 Exp. SC-9618-2015, MP. Fernando Giraldo Gutiérrez.

136 Corte Suprema de Justicia, Sala Civil, 14 de marzo de 2017, Exp. SC3530-2017, MP. Álvaro Fernando García Restrepo. 
o de contratar otro seguro. Sin embargo, el Tribunal Superior consideró que del contrato de mutuo no surgieron obligaciones para la entidad bancaria respecto del contrato de seguro, lo cual implicó el rechazo de las pretensiones del deudor. La Corte no encontró motivo de censura de la decisión de segunda instancia a pesar de que hubiere aprobado la constatación de una violación al deber de información, dicha violación no tuvo entidad suficiente para deprecar la responsabilidad contractual de la entidad bancaria. De esta forma, la Sala Civil validó la concepción difusa del contrato de seguro de vida grupo deudores en la cual el deudorasegurado debía cumplir con las cargas que su calidad le imponían, esto es, el verificar la continuidad del contrato y realizar subsiguientemente el pago de la prima fijada en la póliza, al no haber reconocido un perjuicio de pérdida de oportunidad proveniente de la falta de información de parte de la entidad crediticia.

Más recientemente, el 17 de abril de $2017^{137}$ la Corte Suprema de Justicia validó una visión difusa de la operación. En efecto, la Sala Civil indicó que los beneficiarios de un contrato de seguro establecen relaciones independientes con la aseguradora, al punto que sus vínculos pueden tener naturalezas disímiles, así como mecanismos de revocación y derechos diferenciados, de allí que se consideren como litisconsortes facultativos para fines procesales. Sin embargo, se trató de una providencia sobre la admisión del recurso de casación y por ello su valor normativo no puede ser hasta el momento confirmado.

En suma, hasta el día de hoy solo se puede deducir la fuerza jurídica de una u otra teoría por los motivos expresados en las sentencias analizadas en ausencia de una ratio de la Corte impartiendo en Colombia una directiva sobre el derecho aplicable. Los jueces de instancia cuentan pues con la posibilidad de aplicar la concepción unitaria o la difusa si se respeta la carga argumentativa que les es propia. Sin embargo, consideramos que la utilización indistinta de una u otra teoría puede generar más inconvenientes de los que resuelve y es por ello que a continuación se presenta una solución que comienza a ser tendencia en ordenamientos donde estos debates tienen ya una larga data.

137 Corte Suprema de Justicia, Sala Civil, Auto de 17 de abril de 2017, Exp. SC3530-2017, MP. Álvaro Fernando García Restrepo. 


\section{b. El banco como un intermediario de seguros}

Las teorías unitaria y difusa del contrato de seguro grupo se revelan insuficientes para explicar la complejidad jurídica de este tipo de contratos. Si la utilización de la noción de estipulación por otro no le otorga plenas atribuciones al beneficiario de dicha disposición, no es menos artificial afirmar que la entidad bancaria es externa a un contrato que solo existe entre el deudor y la aseguradora ${ }^{138}$. No se puede, a fuerza de llevar al extremo la interpretación del texto de la ley, considerarse que el banco es parte del contrato de seguro. Del hecho de que un banco-tomador tenga un interés en la relación contractual existente entre sus clientes y el asegurador, así como que tiene unas obligaciones de información frente a los deudores, no se desprende incontestablemente que la entidad crediticia sea parte del contrato de seguro ${ }^{139}$. No es un secreto que las Cortes han utilizado una u otra concepción con el objetivo de proteger un deudor en situación de discapacidad grave o para mantener el margen financiero de la mutualidad de asegurados frente a reclamaciones con sustento insuficiente.

Sin embargo, una nueva teoría de la intermediación surge basada en que recurrir a la estipulación por otro no es ineludible para explicar el vínculo negocial, debido a que la ley reconoce que existen terceros que intervienen en la creación de una relación contractual entre dos partes ${ }^{140}$ sin que éstos tengan necesariamente una calidad contractual frente a ellas. Así, se establece que los corredores de seguros son las personas que, por su especial conocimiento del mercado, se ocupan como intermediarios en la tarea de poner en relación a dos o más personas, con el fin de que celebren un contrato de seguros ${ }^{141}$, sin estar vinculados a las partes por relaciones de colaboración o dependencia ${ }^{142}$. Adicionalmente, categorizados como pro-

138 Boucard, F. (2002) L'analyse juridique de l'assurance de groupe en matière de crédit. Revue générale du droit des assurances, Lextenso - 01/07/2002 - n 2002-03 - page 644, RGDA2002644.

139 Astegiano-La Rizza, A. et Abravanel-Jolly, S. (2011) A la recherche de la juste qualification des liens unissant assureur, souscripteur et adhérents en assurance de groupe, Bulletin Juridique des Assurances BJDA, n 19 Janvier Fevrier 2011.

140 Ibid Op. Cit. Astegiano-La Rizza, A. et Abravanel-Jolly, S. (2011).

141 Definición que surge de la combinación del artículo 1340 del Código de Comercio con el artículo 40 del Estatuto Orgánico del Sistema Financiero que define las sociedades corredoras de seguros como aquellas cuyo objeto social se limita a ofrecer seguros, promover su celebración y obtener su renovación entre el asegurado y el asegurador.

142 En efecto puede haber mandato o representación en los casos de bancassurance sin que se desnaturalicen las funciones de seguro por ir aparejadas a aquellas de crédito. 
veedores de seguros ${ }^{143}$, los intermediarios deben instruir al consumidor sobre los amparos contratados ${ }^{144}$ y las situaciones excluidas de cobertura ${ }^{145}$. Por ello, si se tiene en cuenta que la intervención del establecimiento de crédito tiene lugar para la creación de un contrato de seguros que fue previamente diseñado junto con el asegurador, y que su intervención busca entonces presentar, proponer o ayudar a establecer un contrato de seguros ${ }^{146}$, nada obsta para que el régimen de los intermediarios de seguros les sea aplicable.

Ciertamente, la intervención del banco tiene lugar antes de la del deudor y su objetivo es la creación de un contrato de seguro necesario a la cobertura de sus clientes. Pero ello no significa que deba éste asumir las obligaciones del adherente o incluso las del asegurador. Más aun, no puede afirmarse que se convierte el banco en un garante de la existencia y ejecución del contrato de seguro, como fue la consideración de la Corte Suprema de Justicia en la Sentencia de 28 de mayo de $2015^{147}$. No es entonces una parte al contrato, pero ello no quiere decir que no participó en su creación, y es precisamente dicha intervención, necesaria a la existencia del contrato, lo que explica que unas cargas específicas le sean imputables como intermediario de seguros ${ }^{148}$, específicamente en lo que concierne a la información ${ }^{149}$ sobre la adaptación del producto de seguro al contrato, sobre los requisitos y deberes del adherente ${ }^{150} \mathrm{o}$ incluso para asegurarse de la fiabilidad de la compañía de seguros proponente ${ }^{151}$.

143 Meneses Paternina, J. (2014) El nuevo rol del intermediario de seguros. II Congreso Internacional de Derecho de Seguros, Fasecolda, Santa Marta, mayo de 2014.

$144 \mathrm{Y}$ a este respecto deben informar al usuario en la misma medida que le es exigido a la compañía aseguradora, Transparencia en los contratos de seguros: Vivas Díez, G. J. (2014), Cláusulas e información precontractual, Revista Ibero-Latinoamericana de Seguros RIS, Bogotá (Colombia), 41(23): 39-80, julio-diciembre de 2014.

145 Bérmudez, D., 2013: «El rol del intermediario de seguros», en La industria aseguradora en Colombia. Avances en el siglo XXI. Fasecolda, Bogotá, pag. 622 y ss.

146 Como lo dice el Codigo de Seguros de Francia en su sacro-santo artículo L.511-1 "présenter, proposer ou aider à conclure".

147 Corte Suprema de Justicia, Sala Civil, 28 de mayo de 2015, Exp. SC-6709-2015, MP. Jesús Vall de Rutén Ruíz.

148 Gossou, S. (2007) Impacts du nouveau cadre juridique de l'intermédiation en assurance sur la bancassurance, Revue générale du droit des assurances, Lextenso 01/01/2007 - n 2007-01 - page 21, RGDA200721.

149 Esta obligación les es propia a las entidades bancarias como se establece en el artículo 97 del Estatuto Orgánico del Sistema Financiero.

150 Leducq, X. (2015) Qualité de l'emprunteur et obligation d'alerte du prêteur en matière d'assurance, Gazette du Palais - 15/12/2015 - n 349 - page 21, GPL252k7.

151 Op. Cit. Astegiano-La Rizza, A. et Abravanel-Jolly, S. (2011). 
Una solución como la interpretación de la intervención del establecimiento de crédito en calidad de intermediario de seguros permite entonces mantener unos márgenes claros de los vínculos jurídicos existentes, a la par que permite una protección mayor de los usuarios. En efecto, como ocurre en la Comunidad Europea, se requiere que la entidad bancaria realice un trabajo de asesoría y de verificación de la soldabilidad del candidato al crédito ${ }^{152}$, además de exigírsele de precisar si el contrato que se propone proviene de un análisis objetivo del mercado o si surge de un contrato de exclusividad establecido entre el banco y uno o varios aseguradores ${ }^{153}$ como lo impone igualmente el Código de Consumo de Francia ${ }^{154}$ en la aplicación de la directiva europea explícitamente respecto del banco o intermediario.

En lo que respecta al tipo de información que debe dársele al asegurado, en Singapur si una cláusula del contrato puede privar de derecho al asegurado, debe explicársele al candidato dicha limitación aclarándole que el perímetro del amparo está circunscrito una definición terminológica incluida en póliza. Así, al otorgar información precisa sobre una decisión que puede dejar sin efectividad el contrato de seguro, como se mencionó por Suprime Court en la Decisión Tay Eng Chuan v Ace Insurance Ltd [2008] $]^{155}$ se busca que la persona candidata al seguro pueda discernir si la garantía cumple con sus necesidades de cobertura que busca en dicho servicio.

\section{BIBLIOGRAFÍA}

\section{- Doctrina}

Assurance-vie (2017) Chapitre 1 Section 1, Le cours du contrat de groupe, ElNet Editions Législatives.

Astegiano-La Rizza, A. et Abravanel-Jolly, S. (2011) A la recherche de la juste qualification des liens unissant assureur, souscripteur et adhérents en assurance de groupe, Bulletin Juridique des Assurances BJDA, nº 19 Janvier Fevrier 2011.

152 Directiva 2014/17/UE de 4 de febrero de 2014 del Parlamento Europeo y del Consejo Europeo.

153 La protection des emprunteurs immobiliers renforcée (2016) Editions Francis Lefebvre - La Quotidienne, Au cœur du droit, Immobilier 10/06/2016.

154 C. consom. art. L 313-7 en su nueva redacción.

155 Tay Eng Chuan v Ace Insurance Ltd [2008] 4 SLR(R) 95; [2008] SGCA 26. 
Astegiano-La Rizza, A. et Abravanel-Jolly, S. (2014) La reconnaissance législative de l'assurance collective de dommages, Bulletin Juridique des Assurances BJDA, n. 35 mars-avril 2014.

Astegiano-La Rizza, A. et Abravanel-Jolly, S. (2017) De quelques rappels de règles quant à l'opposabilité des exceptions contractuelles en assurance de groupe, Bulletin Juridique des Assurances BJDA, n. 59 mars-avril 2017.

Bentin-Liaras, M. (2014) La protection par le droit des assurances, Revue générale du droit des assurances, Lextenso - 01/05/2014 - nº 05, RGA110u7.

Bérmudez, D., 2013: «El rol del intermediario de seguros», en La industria aseguradora en Colombia. Avances en el siglo XXI. Fasecolda, Bogotá, pag. 622 y ss.

Bigot, J. (2016) Problématique des assurances collectives de dommages, Revue générale du droit des assurances, Lextenso - 01/10/2016 - n 10 - page 459, RGA113v1.

Boucard, F. (2002) Lsanalyse juridique de l>assurance de groupe en matière de crédit. Revue générale du droit des assurances, Lextenso - 01/07/2002 - n² 2002-03 page 644, RGDA2002644.

Bury, B. (2014) L'inadéquation fonde l'obligation d'éclairer sur l'adéquation. Gazette du Palais, Lextenso, 22/07/2014, n² 203, p. 32, GPL187m3.

Concepto 2014105076-001 de 23 de diciembre de 2014 "Seguro de vida grupo deudores, amparos" Superintendencia Financiera de Colombia.

Conferencia inaugural de la Asociación de Juristas Franco-Colombianos, Paris 9 de junio de 2017.

Contrats emprunteurs (2017) Chapitre 1 Section 1, Dictionnaire permanent assurances, ElNet Editions Législatives.

Courtieu G. (2005) Resp. civ. et assur., LexisNexis Jurisclasseur, Comm. 139.

Donlon, R. L. (2016) Using trade credit insurance in the energy industry, Property Casualty 360, LexisNexis UK, February 26, 2016.

Fecha de calificación de pérdida de capacidad laboral estructura el siniestro en seguro que ampara créditos (2016) Ambito Juridico, Multilegis, 27 de mayo del 2016.

Gossou, S. (2007) Impacts du nouveau cadre juridique de lintermédiation en assurance sur la bancassurance, Revue générale du droit des assurances, Lextenso 01/01/2007 - n² 2007-01 - page 21, RGDA200721.

Kullman, J. (2015) Assurances liées à un crédit et TEG : comment piéger l'emprunteur, Revue générale du droit des assurances, Lextenso, 01/01/2015 - nº 01 - page 7, RGA111t3. 
Kullman, J. et al. (2017) LamyLine, Lamy Assurances 2017, Wolters Kluwer France.

La protection des emprunteurs immobiliers renforcée (2016) Editions Francis Lefebvre - La Quotidienne, Au cœur du droit, Immobilier 10/06/2016.

Leducq, X. (2015) Qualité de l'emprunteur et obligation d'alerte du prêteur en matière d'assurance, Gazette du Palais - 15/12/2015 - n 349 - page 21, GPL252k7.

Manrique Chaves, D. M. (2016) La sobreconstitucionalización del derecho de seguros: El compañero permanente o cónyuge del mismo sexo como beneficiario a título legal en el seguro de vida, 44 Rev.Ibero-Latinoam.Seguros RIS, 91-139

Mejía Aramburo, S. (2017) La desintermediación en el contrato de seguro. De la bancaseguros al uso de red, 46 Rev.Ibero-Latinoam. Seguros RIS, 109-148.

Meneses Paternina, J. (2014) El nuevo rol del intermediario de seguros. II Congreso Internacional de Derecho de Seguros, Fasecolda, Santa Marta, mayo de 2014.

Narváez Bonnet, J.E. (2013) Legitimación de la viuda y de los herederos bajo el seguro de vida grupo deudores, Revista Ibero-Latinoamericana de Seguros, RIS, Bogotá (Colombia), 39(22): 69-111, julio-diciembre de 2013.

Nicolas, V. (2015) Le banquier, mandataire de l>assureur dans les assurances de groupe ?, L'Essentiel de droit des assurances, Lextenso, 16/09/2015 - n 08 - page 1, EDAS2015111.

Ordóñez Ordóñez, A. (2001) El carácter Indemnizatorio del Seguro de Daños, Rev. Derecho Privado, n.3 (7).

Ramirez-Gómez, J.F. (2015) Legitimación del cónyuge sobreviviente y de los herederos con ocasión de los contratos de seguros de vida grupo deudores, Revista IberoLatinoamericana de Seguros RIS, 103-121 (2015).

Rapport au Président de la République relatif à l'ordonnance n²016-131 du 10 février 2016 portant réforme du droit des contrats, du régime général et de la preuve des obligations JORF $n^{\circ} 0035$ du 11 février 2016 texte $\mathrm{n}^{\circ} 25$.

Ridley N. (2011) Greater detail on credit risk and political risk, Insurance Disputes, Ch. 22, Insurance against pecuniary loss, 3rd Ed. i-Law, p. 20-26.

Rojas López, Miguel David, Bran Rueda, Nelson Yovany, \& Rincón López, Carolina. (2013). Mortgage Financing Model For Housing. Case study: Mexico, Chile and Colombia. Revista Ingenierías Universidad de Medellín, 12(22), 97-108.

Valerie Du ToitLow; GohLow Soen Yin; Lee Kiat Seng (2005) Insurance Law, No.24.1.8, Singapore Law, i-Law. 
Vivas Díez, G. J. (2014), Cláusulas e información precontractual, Revista Ibero-Latinoamericana de Seguros RIS, Bogotá (Colombia), 41(23): 39-80, julio-diciembre de 2014.

Zarante Bahamón, G. (2016) Constitucionalización y protección de derechos fundamentales en el contrato de seguro: Análisis jurisprudencial-Corte Constitucional de Colombia, 45 Rev.Ibero-Latinoam.Seguros RIS, 233-268.

\section{- Sentencias y laudos de Colombia}

Corte Suprema de Justicia, Sala Civil, 19 de mayo de 1999, Exp. 4923, MP. José Fernando Ramírez Gómez.

Corte Suprema de Justicia, Sala Civil, 23 de marzo de 2004, Exp. 14576, MP. Silvio Fernando Trejos Bueno.

Corte Suprema de Justicia, Sala Civil, 29 de agosto de 2000, Exp. 6379, MP. Jorge Santos Ballesteros.

Corte Suprema de Justicia, Sala Civil, 25 de mayo de 2005, Exp. C-7198, MP. Jaime Alberto Arrubla Paucar.

Corte Suprema de Justicia, Sala Civil,6 de julio de 2007 Exp. 0359-01, MP. Carlos Ignacio Jaramillo Jaramillo.

Corte Suprema de Justicia, Sala Civil, 16 de mayo de 2011, Exp. 9221-01, MP. Ruth Marina Díaz Rueda.

Corte Suprema de Justicia, Sala Civil, 30 de junio de 2011 Exp. 0019-01, MP. Edgardo Villamil Portilla.

Corte Suprema de Justicia, Sala Civil, 22 de abril de 2013, Exp. 0187-01, MP. Fernando Giraldo Gutiérrez.

Corte Suprema de Justicia, Sala Civil, 5 de mayo de 2014 Exp. SC-5189-2014, MP. Margarita Cabello Blanco.

Corte Suprema de Justicia, Sala Civil, 29 de mayo de 2015, Exp. SC-6709-2015, MP. Jesús Vall de Rutén Ruíz.

Corte Suprema de Justicia, Sala Civil, 27 de julio de 2015 Exp. SC-9618-2015, MP. Fernando Giraldo Gutiérrez.

Corte Suprema de Justicia, Sala Civil, 4 de marzo de 2016, Exp. n SC803-2016.

Corte Suprema de Justicia, Sala Civil, 14 de marzo de 2017, Exp. SC3530-2017, MP. Álvaro Fernando García Restrepo. 
Corte Suprema de Justicia, Sala Civil, Auto de 17 de abril de 2017, Exp. SC3530-2017, M. Aroldo Wilson Quiroz Monsalvo.

Delegatura para Funciones Jurisdiccionales de la Superintendencia Financiera, Sentencia 2014-1167, sep. 11/15.

Nubiola Colombia Pigmentos S.A. contra La Compañía Mundial de Seguros S.A., 21 de Junio de 2.010, Árbitro único Ricardo Vélez Ochoa.

\section{- Sentencias de Francia}

Cass. 1re civ., 22 janv. 2009, no 07-19.867.

Cass. 1re civ., 1er févr. 2005, no 03-18.795.

Cass. 1re civ., 12 mars 2002, no 00-21.271.

Cass. ass. plén., 2 mars 2007, no 06-15.267.

Cass. 1re civ., 9 juin 1998, no 96-13.708.

Cass. com., 1er déc. 2015, n 14-22134.

Cass. ass. plén., 2 mars 2007, no 06-15.267.

\section{- Case-law de Singapur}

Lee Pey Woan; Tham Chee Ho (2009), Contract Law 10 SAL Ann Rev 194 Singapore Academy of Law Annual Review.

NTUC Cooperative Insurance Commonwealth Enterprise Ltd v Chiang Soong Chee [2007] SGHC 222.

Pender Development Pte Ltd and another v Chesney Real Estate Group LLP [2009] 3 SLR(R) 1063; [2009] SGHC 126.

TKM (Singapore) Pte Ltd v Export Credit Insurance Corp of Singapore Ltd [1992] 2 SLR(R) 858.

Tay Eng Chuan v Ace Insurance Ltd [2008] 4 SLR(R) 95; [2008] SGCA 26. 